C-A/AP/\#201

May 2005

\title{
Numerical Simulation on Nitrogen Migration and ODH in RHIC Tunnel
}

L. Jia

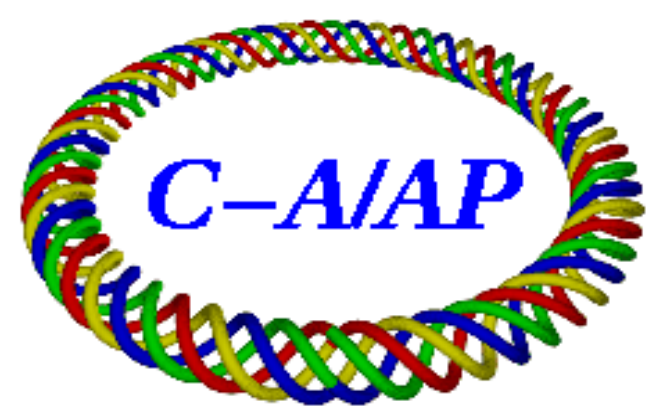

Collider-Accelerator Department

Brookhaven National Laboratory

Upton, NY 11973 


\title{
Numerical Simulation
}

on

\section{Nitrogen Migration and ODH in RHIC Tunnel}

\author{
Lin Xiang Jia
}

February, 2005

Collider-Accelerator Department

Brookhaven National Laboratory

Upton, NY 11973 


\section{Introduction}

An investigation by numerical simulation to reveal possible oxygen deficiency hazards caused by controlled and uncontrolled release of nitrogen purge gas into the RHIC tunnel was initiated by the Accelerator Systems Safety Review Committee (See Appendixes).

A computational fluid dynamics package, FLUENT, was used to carry out the numerical simulation on mole fraction of oxygen in the tunnel by means of three dimensional and transient. This report presents the simulation results by providing the data in contour and profile plots in space and time.

The species modeled include only oxygen and nitrogen, no other chemical species are considered. A multiple species mass transfer model with effects of gravity acceleration is applied. The Fick's law is used to model diffusion of chemical species in turbulent flows as:

$$
J_{i}=-\left(\rho D_{i, m}+\mu_{t} / S c_{t}\right) \nabla Y_{i}-D_{T, i} \nabla T / T
$$

Where $D_{i, m}$ is the mass diffusion coefficient for species $i$ in the mixture in laminar flow and $D_{T, i}$ is the thermal diffusion coefficient, $S c_{t}$ is the effective Schmidt number for the turbulent flow.

The physical model of RHIC tunnel is determined by taking the information provided in Appendixes, which is somewhat simplified according to the limitation of the numerical package and the knowledge of author as well.

The work is divided in a fashion of five study CASES in order to emphasize the focus and to deal with the problem under different initial and boundary conditions. For each CASE, the physical model is illustrated in a schematic depicting the cross section and a length of one sextant. Only one sextant is modeled. A brief description for each CASE is also provided for flow arrangement with the space and time information.

In the first part of the simulation, the curvature of the tunnel was taken into account, which was found later that some post processing advantages were sacrificed in different coordinate system. In later part, the tunnel was treated as straight and only half of the tunnel was modeled for its symmetry. The difference of the curved or straight tunnel modeled has been proved trivial. Results by both methods are presented in the report.

For the CASE of "squirrel-cage" and "elephant trunk" in the last section, section 5, of this report provides some discussions in detail for the effect of two different discharging directions.

The author thanks Woody Gleen and Gary McIntyre for providing the necessary information helping to complete this work. 


\section{CASE I}

(1) One curvature sextant of tunnel is modeled.

(2) No blowing fan and no leaking out in the sextant.

(3) At time $=0$, the tunnel is full of air $(20.946 \% \mathrm{O} 2+78.084 \% \mathrm{~N} 2$ by Mole or $23.2 \%+75.5 \%$ by Mass).

(4) At time $>0$, gaseous $\mathrm{N} 2$ at $5.4 \mathrm{~g} / \mathrm{s}(10 \mathrm{CFM})$ at room temperature $(300 \mathrm{~K})$ is discharging into the tunnel at a spot somewhere near the center of sextant.

(5) Geometry model is shown in following figure. A coordinate system is shown in the figure.

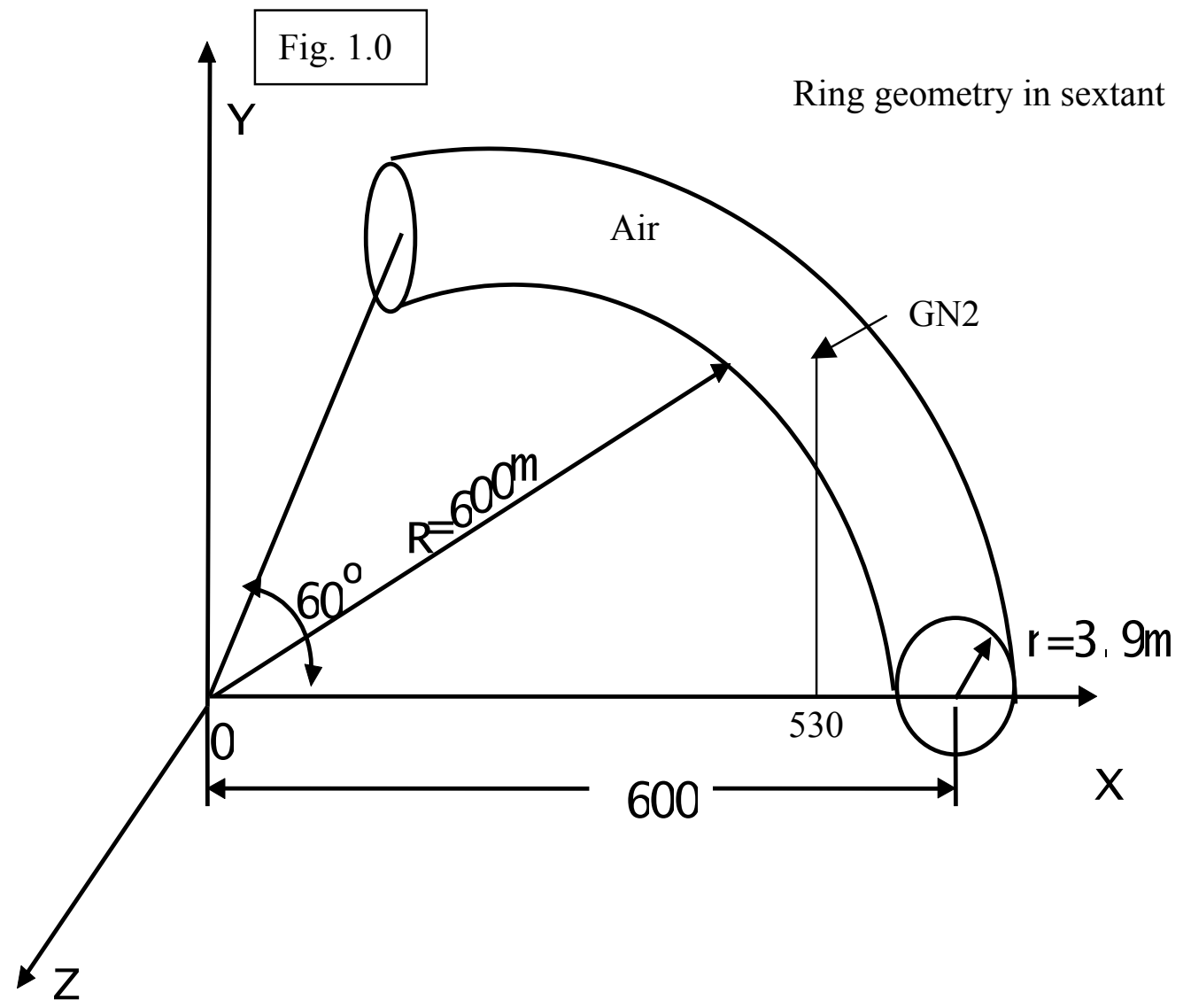


1.1 Contour of mole fraction of $\mathrm{O} 2$ at $\mathrm{t}=65 \mathrm{~s}$. Nitrogen is symmetrically diffusing along the tunnel. The lowest oxygen concentration is higher than $19.4 \%$.

Fig. 1.1

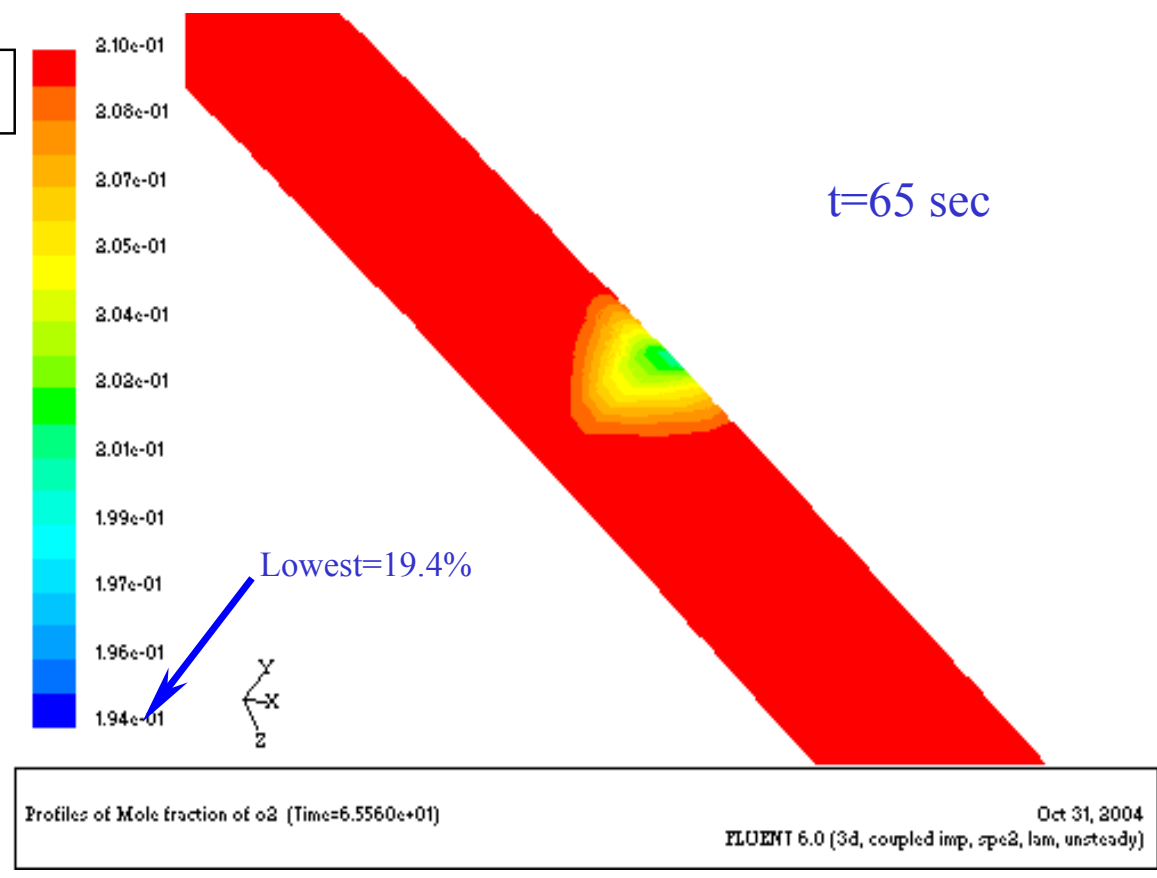

1.2 Contour of mole fraction of $\mathrm{O} 2$ at $\mathrm{t}=648 \mathrm{~s}$. Nitrogen is symmetrically diffusing along the tunnel. The lowest oxygen concentration is still higher than $19.4 \%$, slightly dropped in a small fraction of percentage, not shown in the color bar.

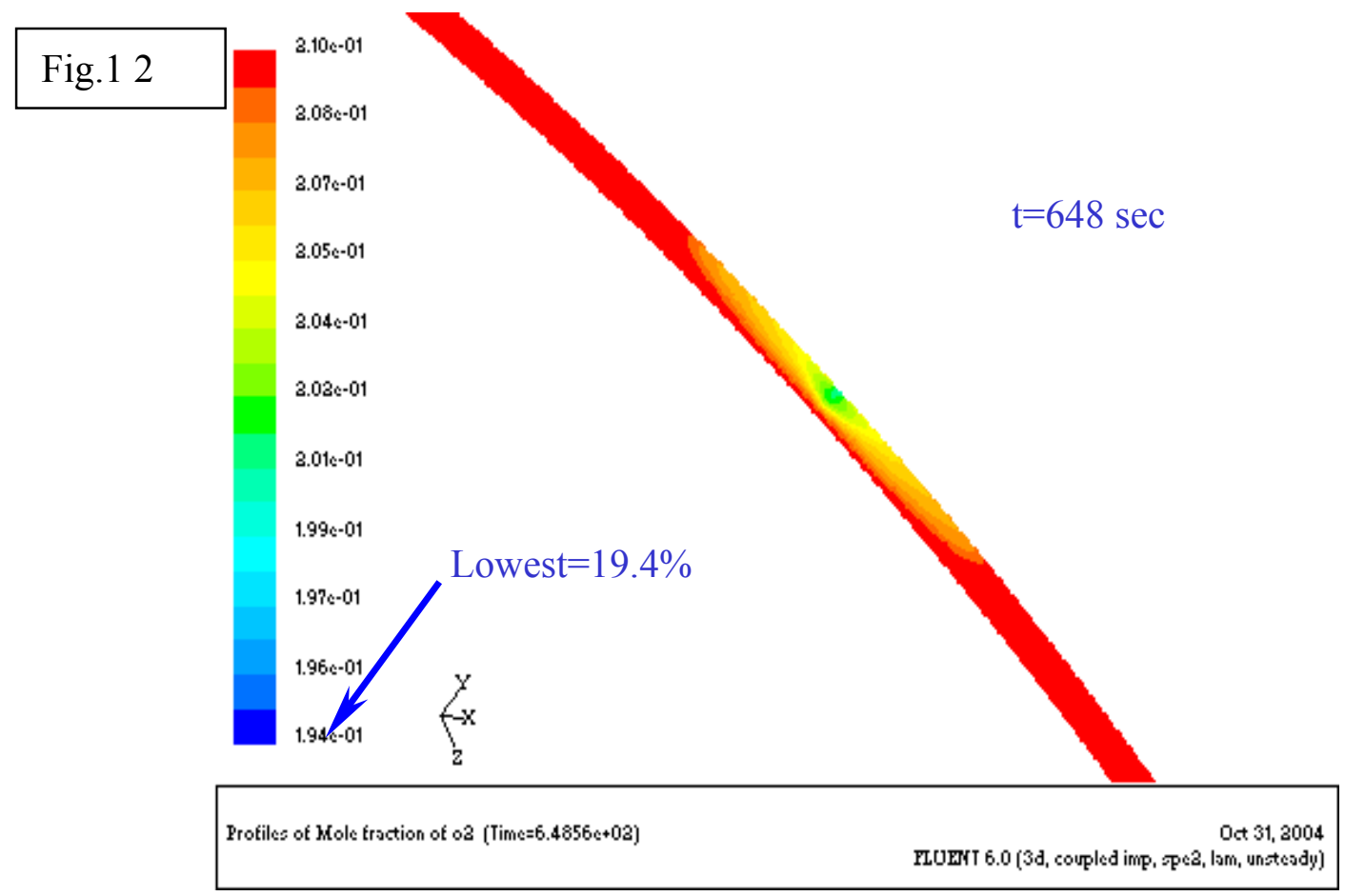


1.3 Contour of mass fraction of $\mathrm{O} 2$ at $\mathrm{x}=530 \mathrm{~m}$ (near discharging point) at $\mathrm{t}=648 \mathrm{~s}$. The cutting plan is elliptic shape and off centered, because it is parallel to $\mathrm{x}$ direction.

Fig. 1.3

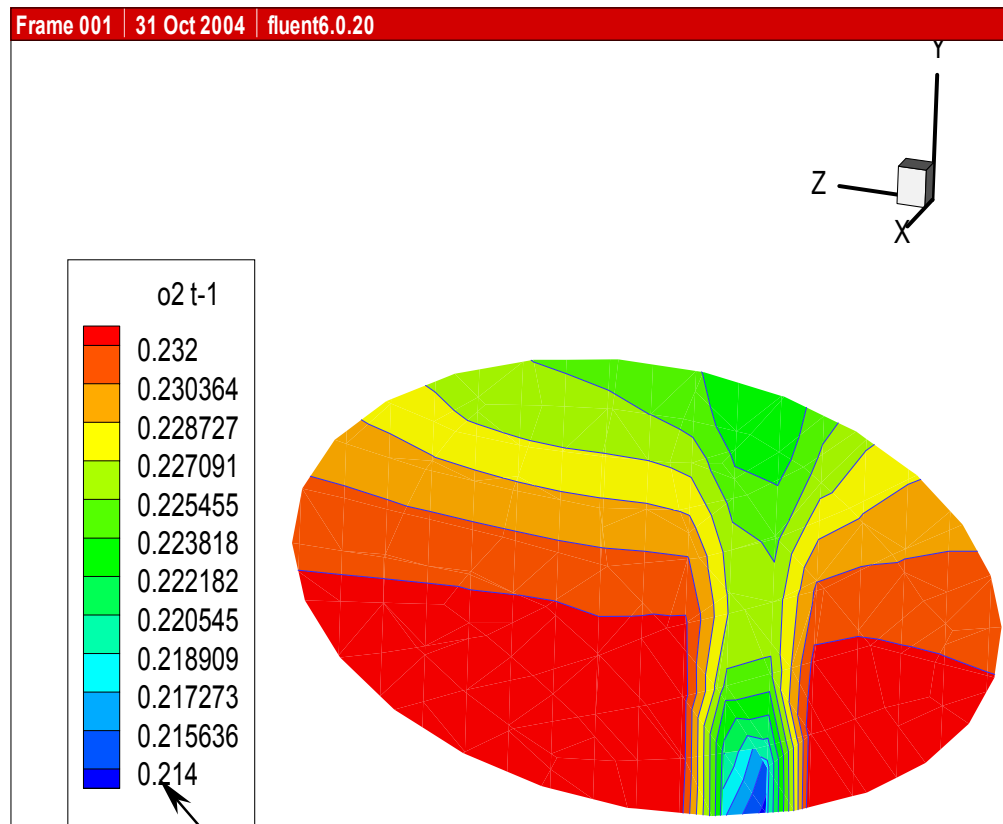

Lowest $=0.194$ in volume

1.4 Mole fraction of $\mathrm{O} 2$ at different height of tunnel along $\mathrm{x}$ direction at $\mathrm{t}=648 \mathrm{~s}$.

Setting $\mathrm{y}=0$ at bottom of tunnel, mole fractions of $\mathrm{O} 2$ are given at $\mathrm{y}=0.5 \mathrm{~m}$ (black), $\mathrm{y}=1.8 \mathrm{~m}$ (red), $\mathrm{y}=7.8 \mathrm{~m}$ (green), respectively, along $\mathrm{z}$ direction.

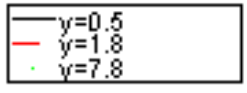

Fig. 1.4

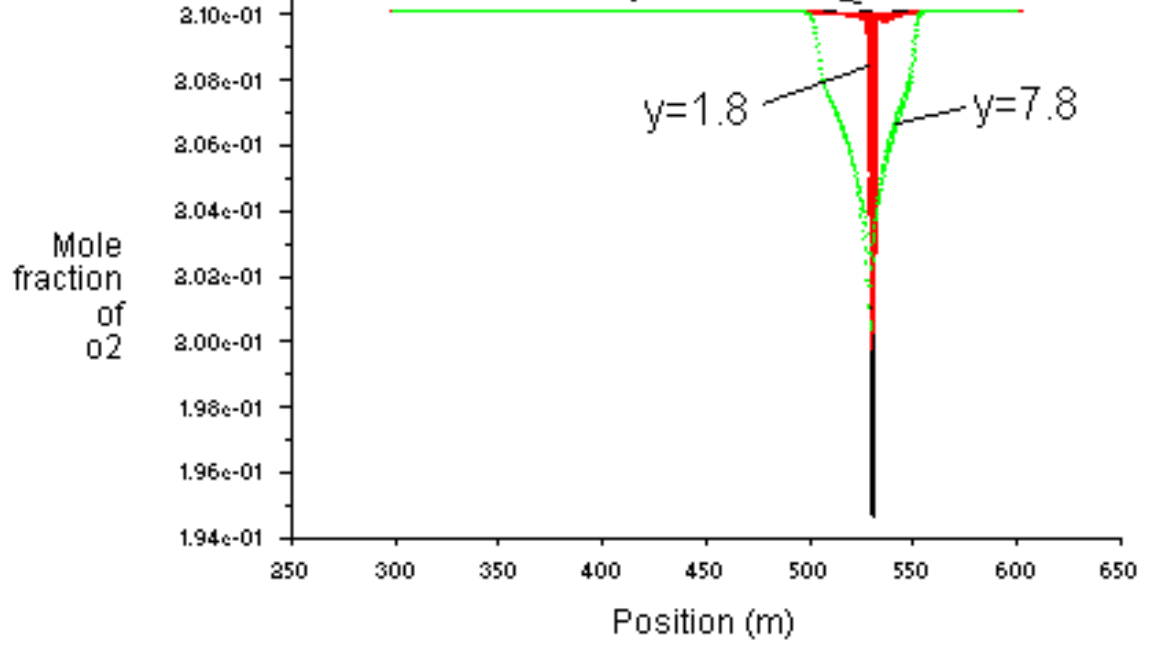

Wole fraction of o3 (Time $=6.4856 \mathrm{c}+02$ )

$0+51,3004$

FIORN 6.0 (3d, coupled imp, Fe?, lom, unstevdy) 
1.5 Mole fraction of $\mathrm{O} 2$ at $\mathrm{t}=2948 \mathrm{~s}$. The lowest oxygen concentration is still higher than $19.4 \%$.

Fig. 1.5
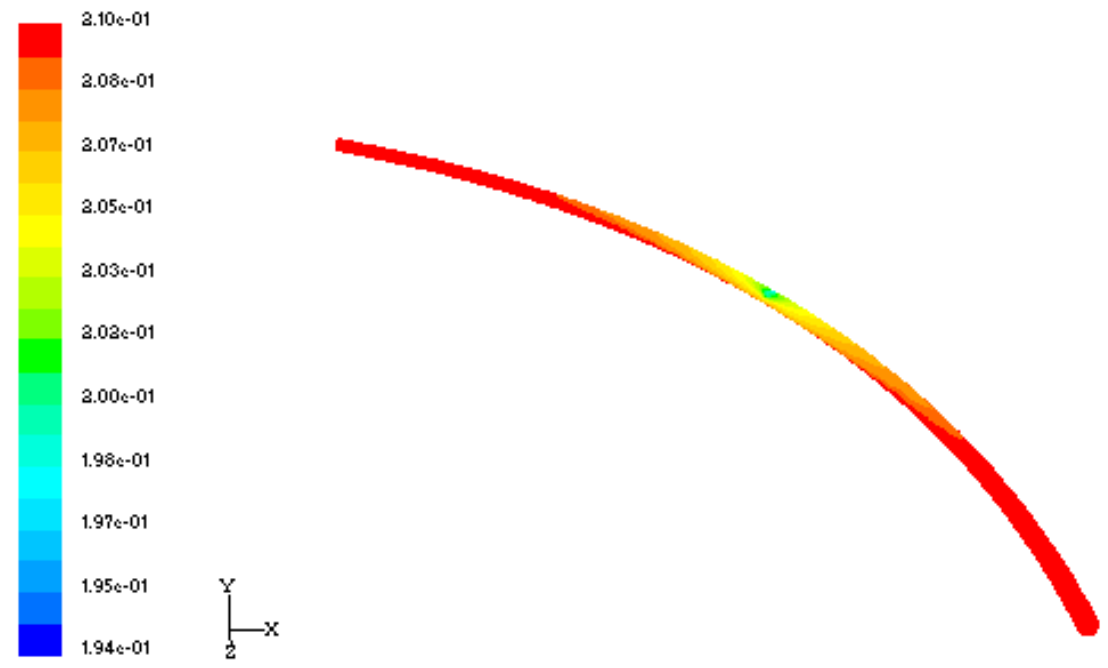

1.6 Mole fraction of $\mathrm{O} 2$ at different heights of tunnel along $\mathrm{x}$ position at $\mathrm{t}=2948 \mathrm{~s}$.

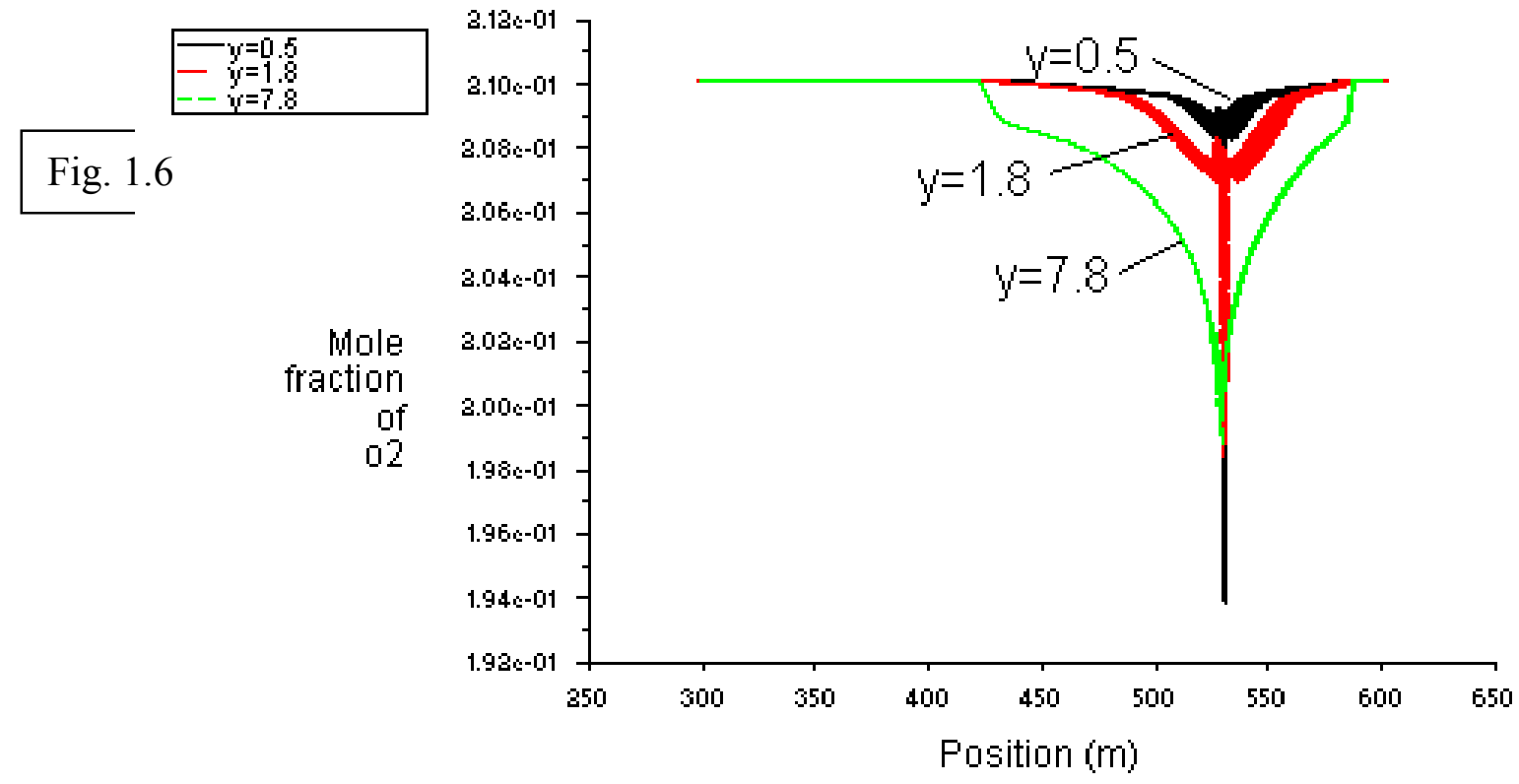


1.7 Mole fraction of $\mathrm{O} 2$ at $\mathrm{t}=11949 \mathrm{~s}$ ( $\sim 200$ minutes), The lowest $\mathrm{O} 2$ concentration is higher than $18.9 \%$.

Fig. 1.7

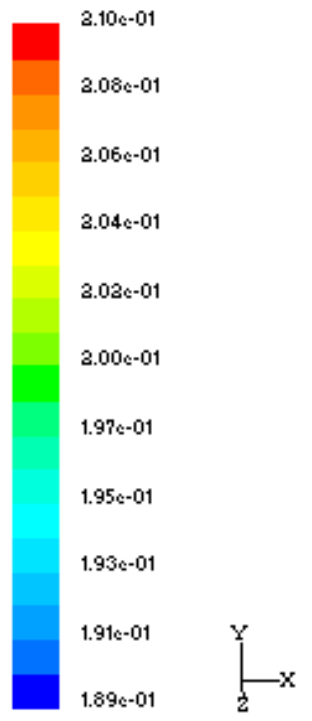

Contours of Wole traction of o3 (Time $=1.1949 \mathrm{c}+04)$

$0+31,3004$ FLUENT 6.0 (3d, coupled imp, Fec2, lam, unatesdy)

1.8 Mole fraction of O2 at different height of tunnel along $\mathrm{x}$ direction, $\mathrm{t}=11949 \mathrm{~s}(\sim 200$ minutes)

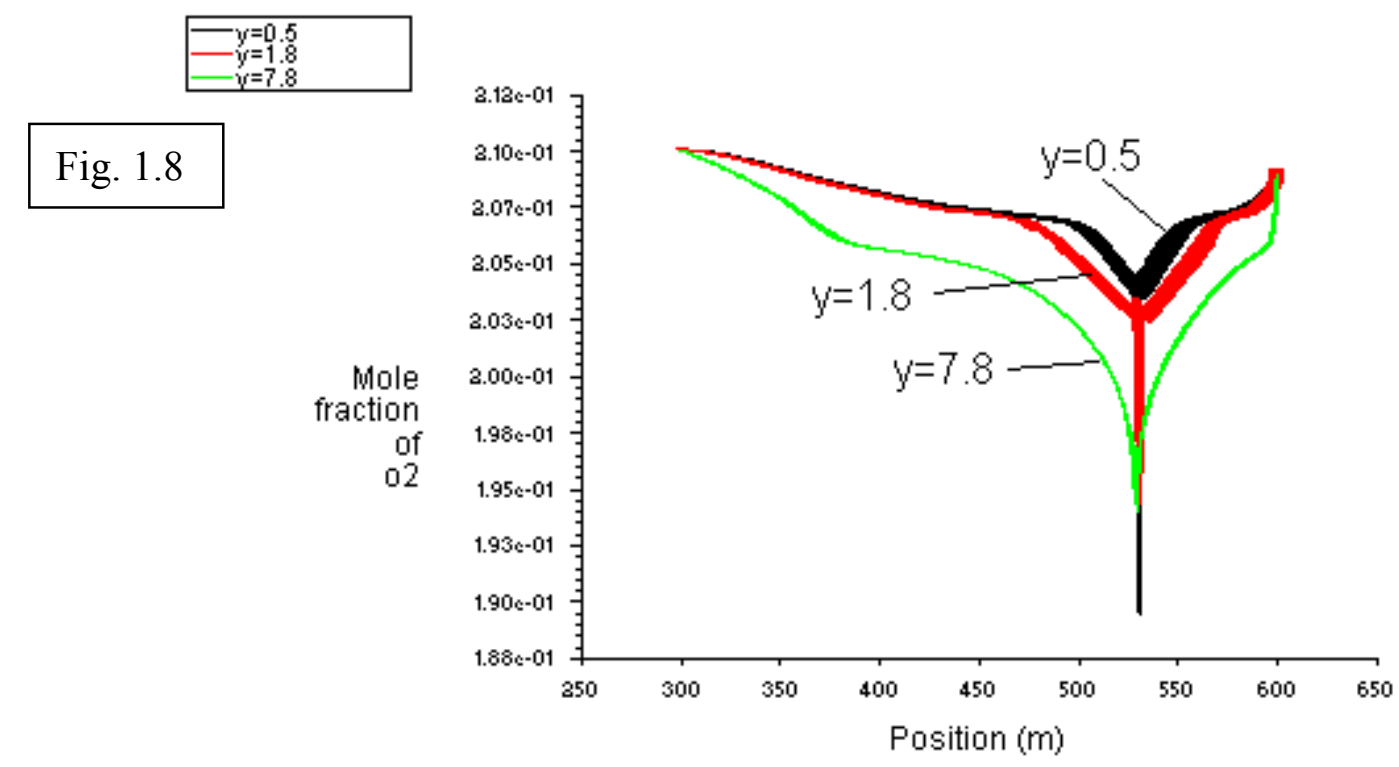


1.9 Contour of mass fraction of $\mathrm{O} 2$ at $\mathrm{x}=450 \mathrm{~m}$ at $\mathrm{t}=48249 \mathrm{~s}(\sim 800 \mathrm{~min})$

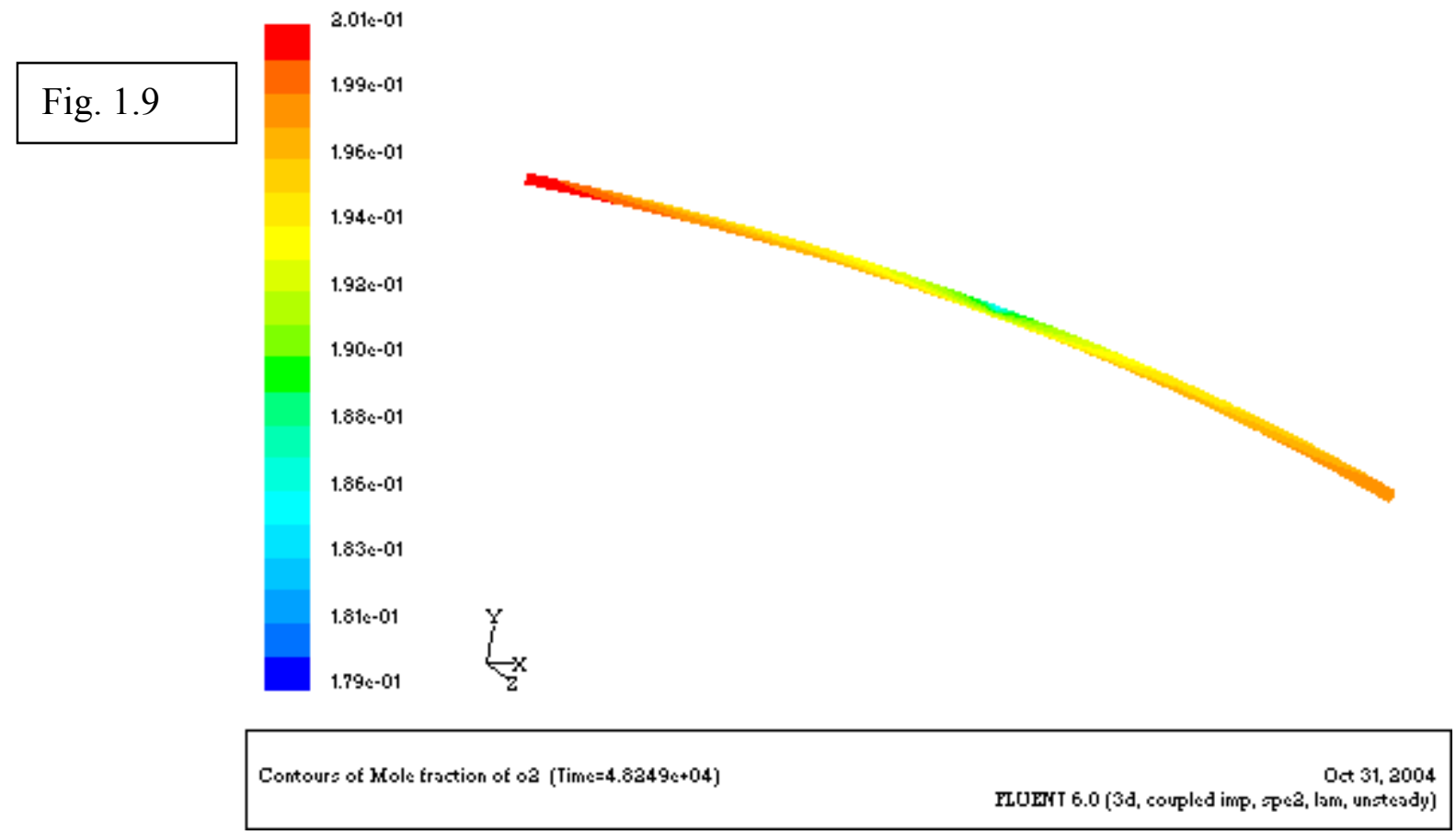

1.11 Contour of mass fraction of $\mathrm{O} 2$ at $\mathrm{x}=450 \mathrm{~m}$ at $\mathrm{t}=48249 \mathrm{~s}$. The cutting plan is elliptic shape and off centered, because it is parallel to $\mathrm{x}$ direction.

Fig. 1.10

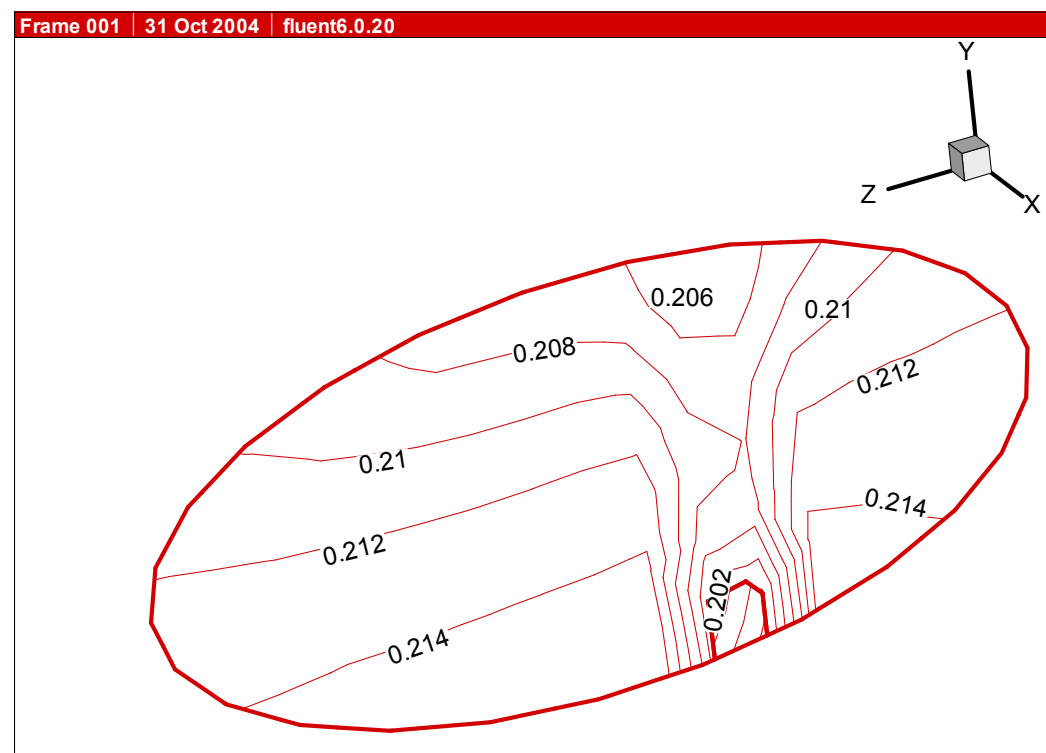


1.11 Mole fraction of $\mathrm{O} 2$ at different height of tunnel along $\mathrm{x}$ direction, $\mathrm{t}=48249 \mathrm{~s}(\sim 13 \mathrm{hrs})$

Fig. 1.11
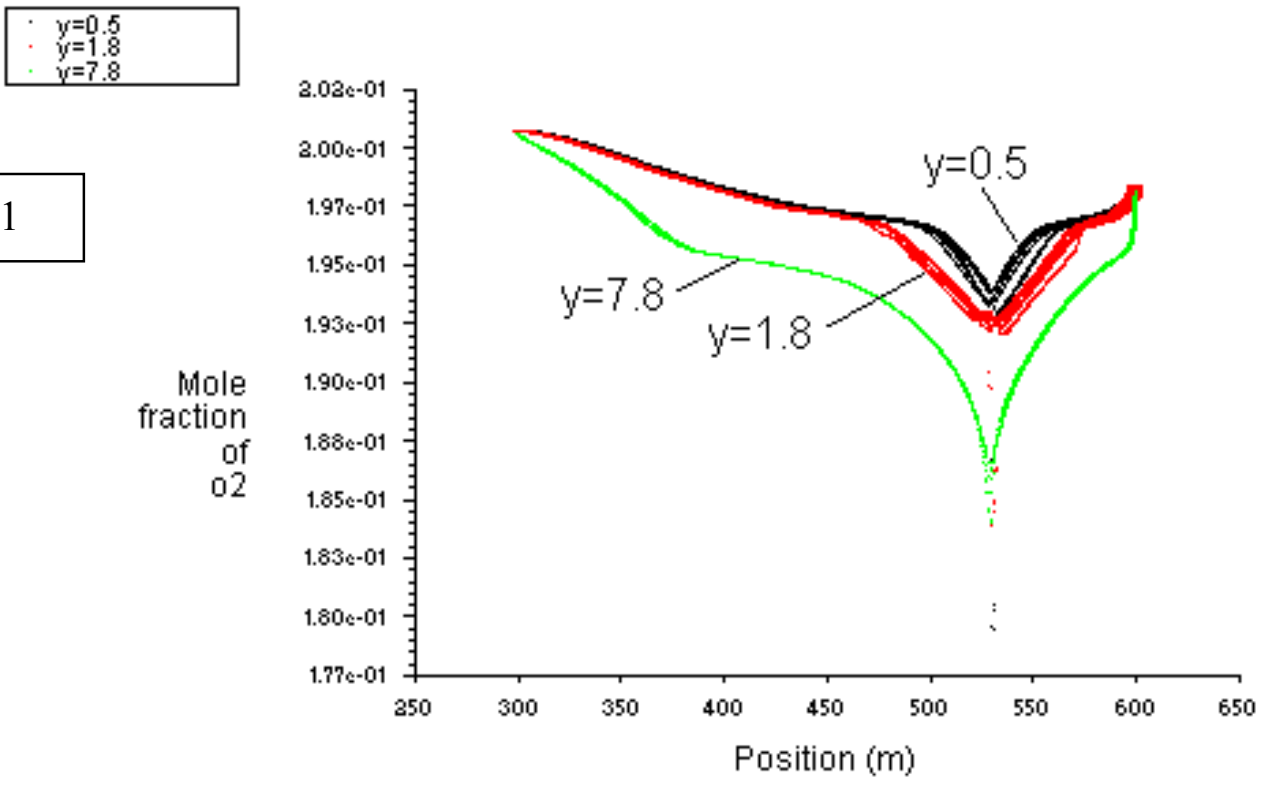


\section{CASE II}

Similar to CASE I except that the mixed gas is leaking out of the sextant at one end. The discharging point of GN2 is at $\mathrm{x}=570 \mathrm{~m}$ close to one end that is different from CASE I.

Fig. 2.0

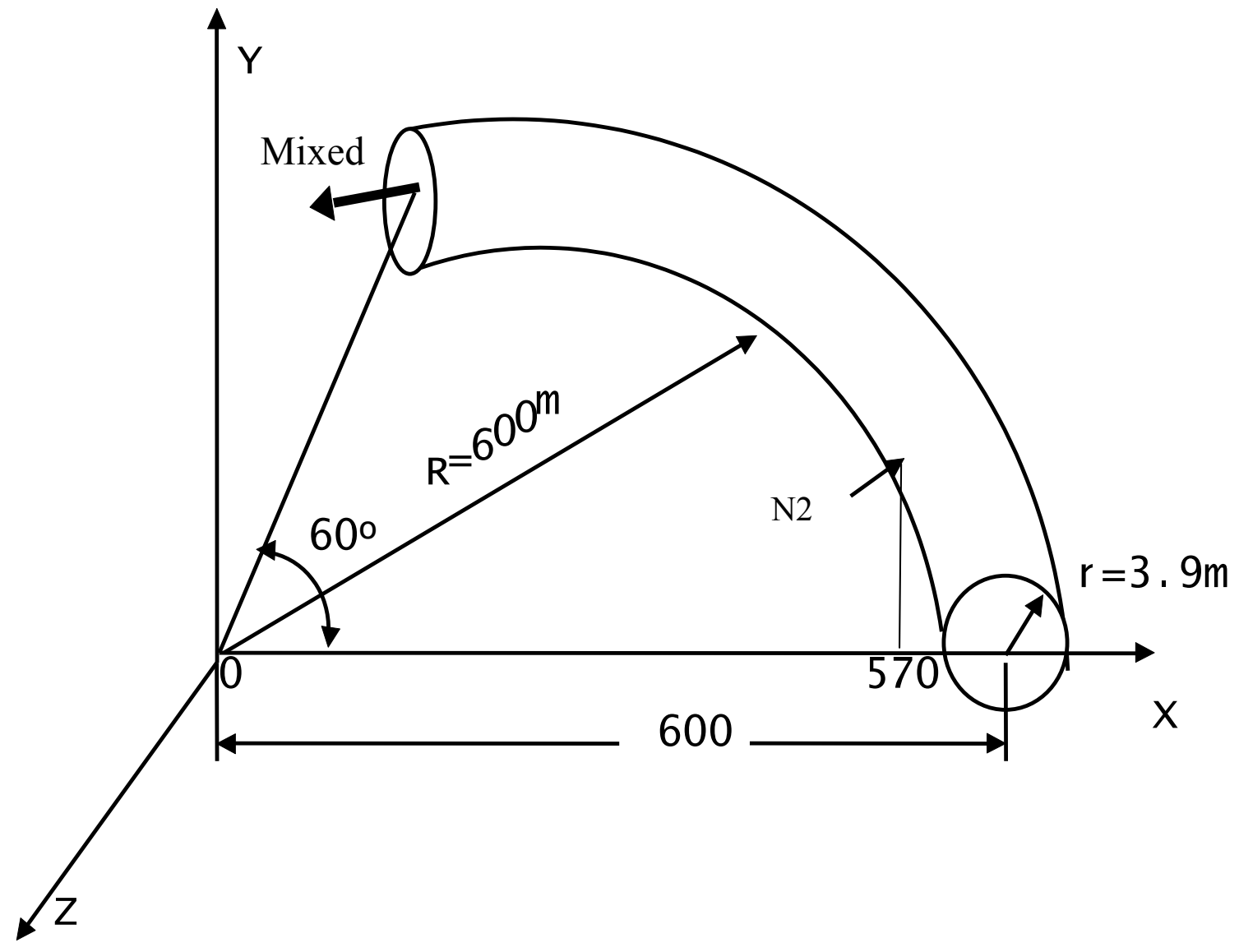


2.1 Mole fraction of $\mathrm{O} 2$ at $\mathrm{t}=59 \mathrm{~s}$, the lowest $\mathrm{O} 2$ concentration is higher than $17.7 \%$.

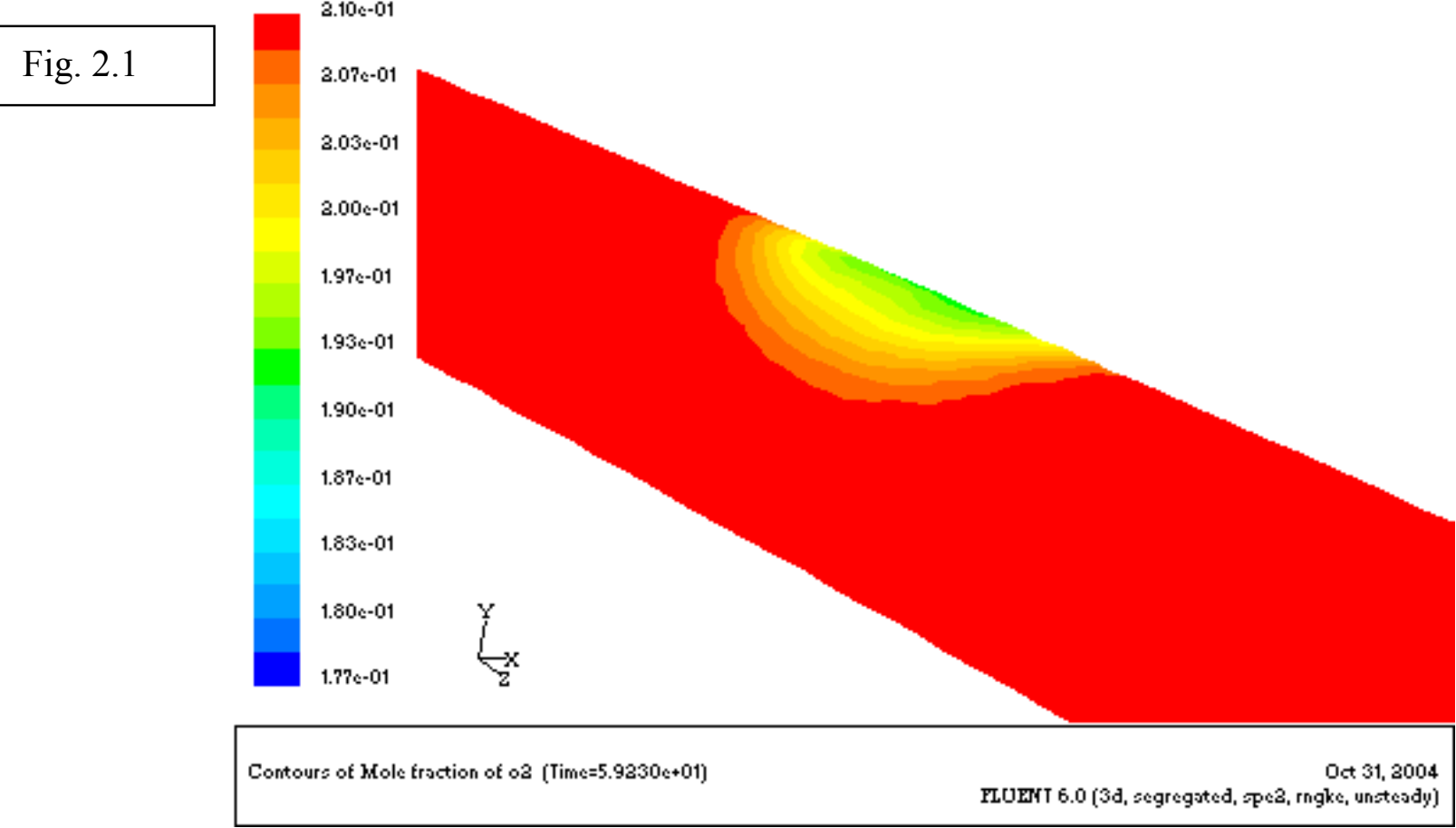

2.2 Mole fraction of $\mathrm{O} 2$ at $\mathrm{t}=259 \mathrm{~s}$, the lowest $\mathrm{O} 2$ concentration is still higher than $17.7 \%$ but in a large affected area.

Fig. 2.2

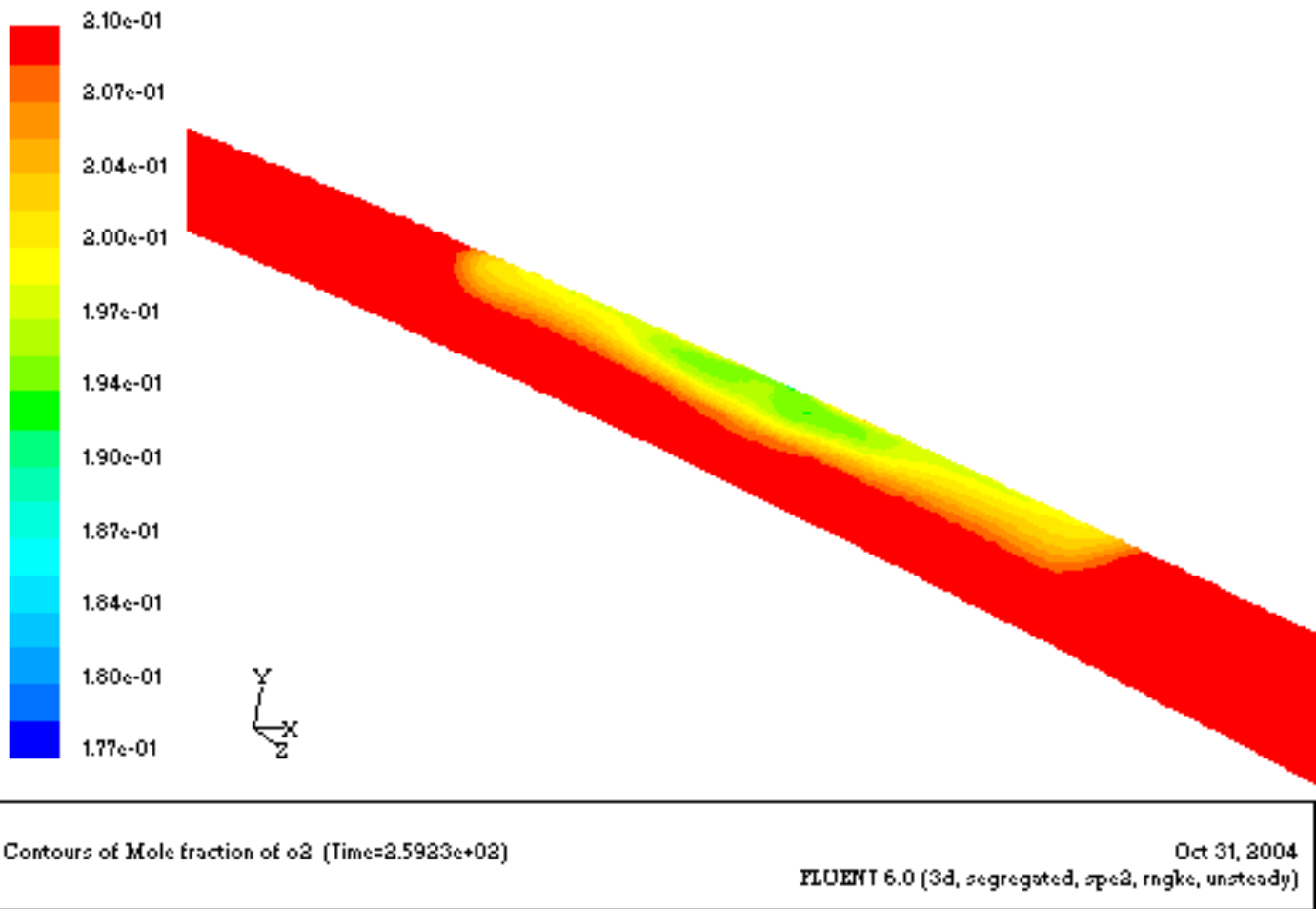


2.3 Mole fraction of $\mathrm{O} 2$ at different heights of tunnel along $\mathrm{x}$ position. $\mathrm{t}=259 \mathrm{~s}$.

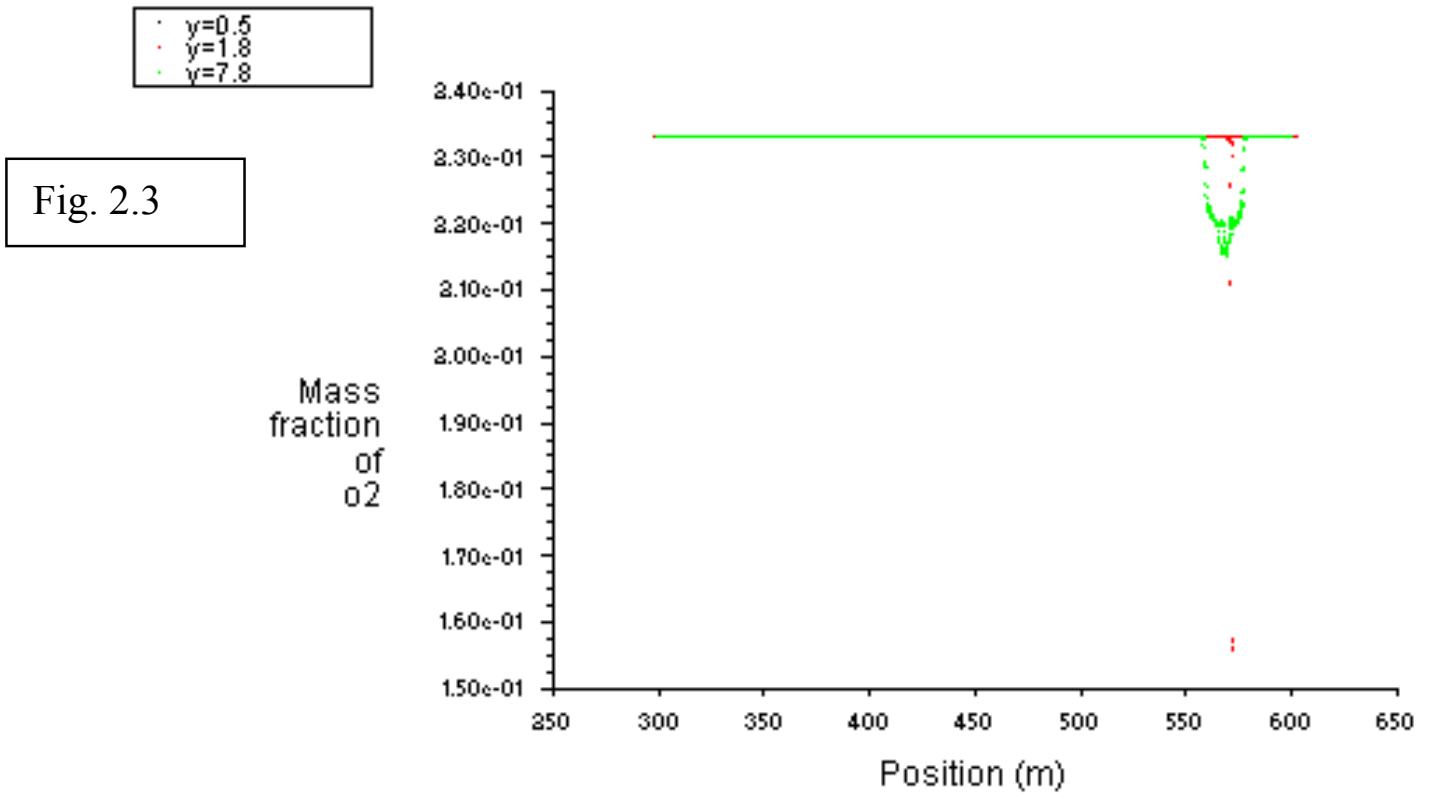

2.4 Mole fraction of $\mathrm{O} 2$ at different heights of tunnel along $\mathrm{x}$ position. $\mathrm{t}=2159 \mathrm{~s}$.

Fig. 2.4

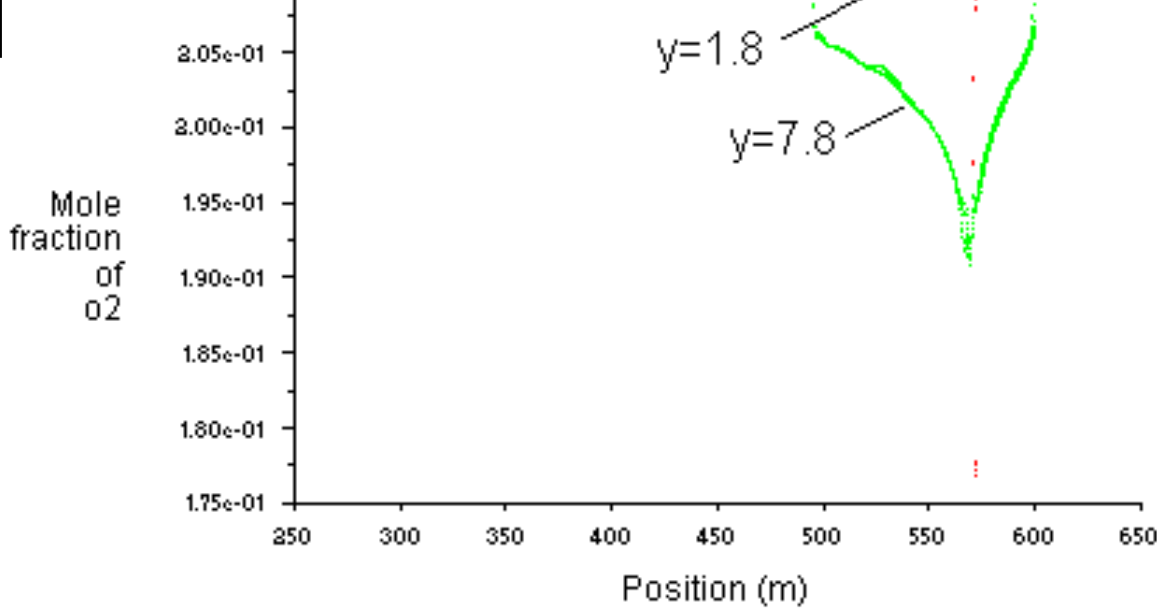


2.5 Mole fraction of $\mathrm{O} 2$ at different heights of tunnel along $\mathrm{x}$ position. $\mathrm{t}=3989 \mathrm{~s}$.

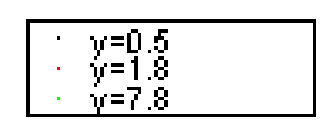

Fig. 2.5

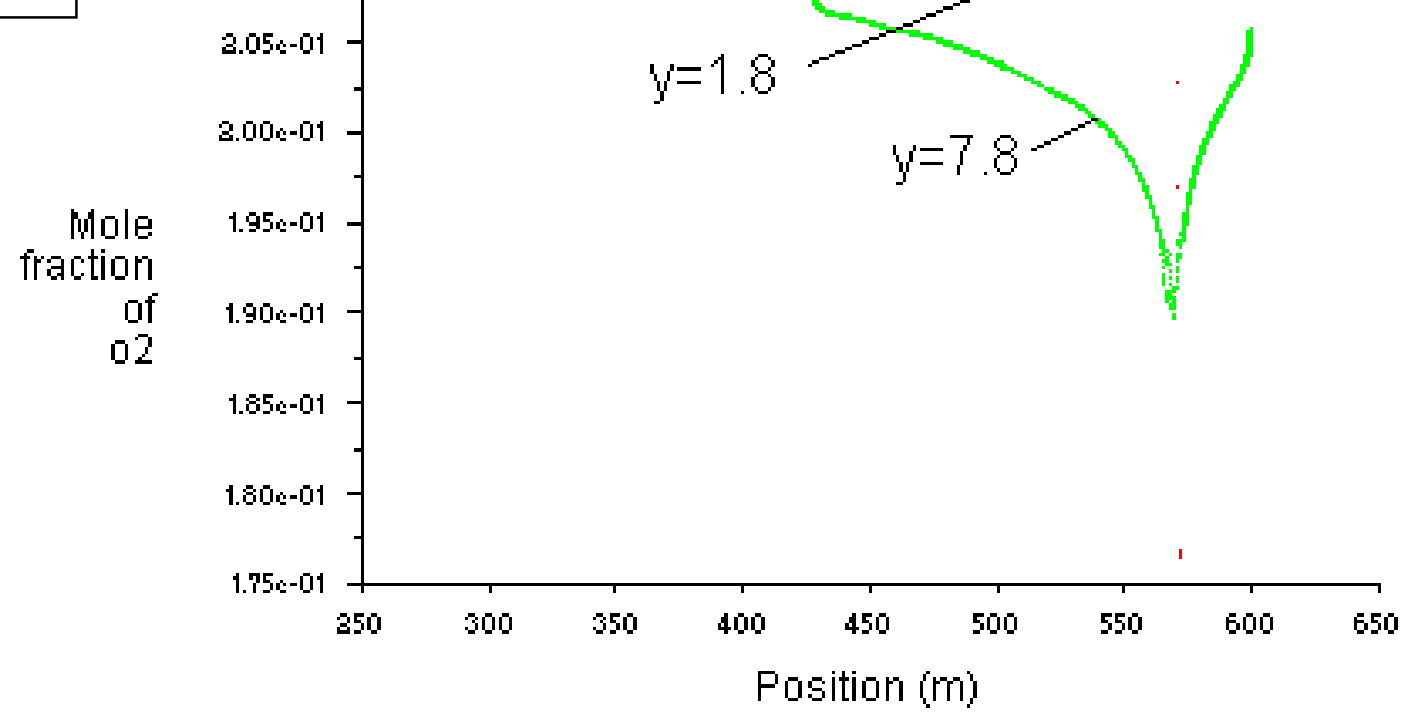




\section{CASE III}

The physical model is shown in Fig. 3.0, the curvature of the sextant is neglected. The GN2 at $\mathrm{z}=10 \mathrm{~m}$ is discharging into the sextant at flow rate of 10CFM. An outlet is at the other end of the sextant, which keeps the pressure in sextant constant by discharging mixed gas out of the sextant at the same flow rate.

Fig. 3.0

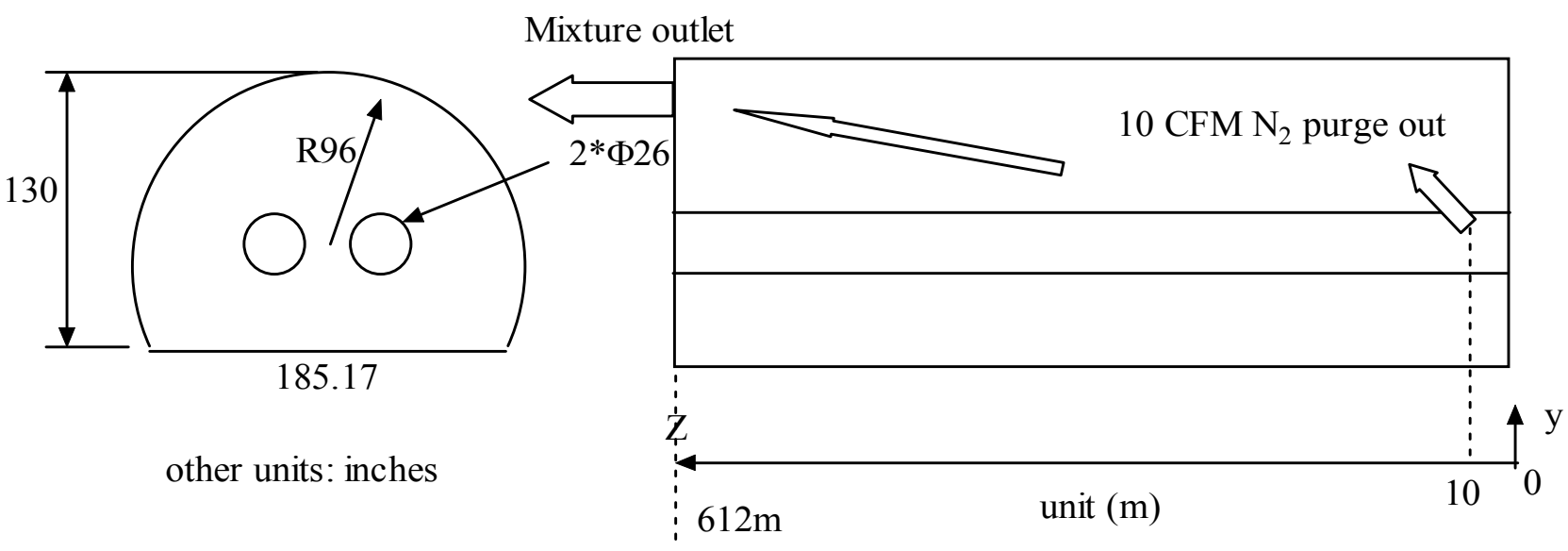


3.1 Mole fraction of O2 at $\mathrm{t}=2619 \mathrm{~s}$, the lowest $\mathrm{O} 2$ fraction is higher than $18.4 \%$. The discharging point is at $\mathrm{z}=10 \mathrm{~m}$, where presents the lowest $\mathrm{O} 2$ mole fraction. The discharging point is at the southeast side of the yellow ring at a view facing the cross section.

\section{Fig. 3.1}

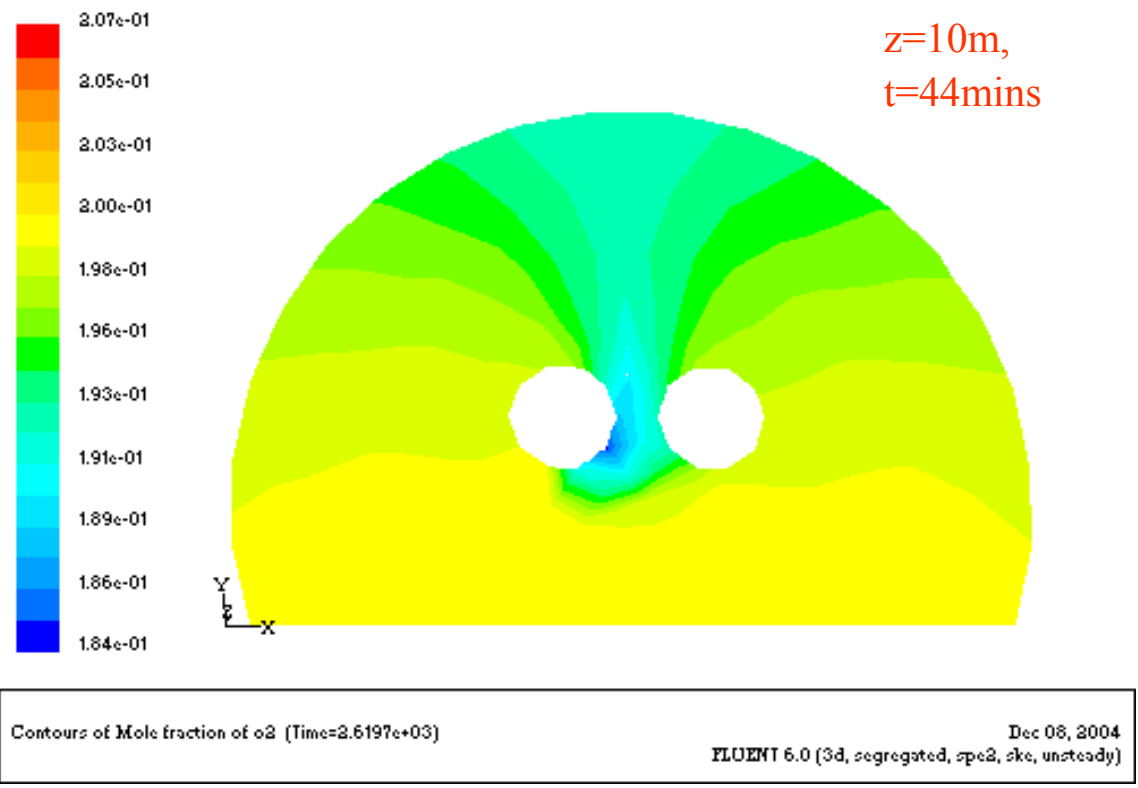

3.2 The $\mathrm{O} 2$ mole fraction profile at a height of $1.8 \mathrm{~m}$ above the ground of tunnel, along the axial direction of the sextant. It is $20.25 \%$ at $\mathrm{t}=860 \mathrm{~s}$ and $19.75 \%$ at $\mathrm{t}=2620 \mathrm{~s}$. In a range between $\mathrm{z}=10 \mathrm{~m}$ and $\mathrm{z}=40 \mathrm{~m}$ along the tunnel (at $\mathrm{y}=1.8 \mathrm{~m}$ ), the $\mathrm{O} 2$ level increases from $20.25 \%$ to normal air at $\mathrm{t}=860 \mathrm{~s}$. At $\mathrm{t}=2620 \mathrm{~s}$ the lowest is $19.75 \%$ and extended to normal air at $\mathrm{z}=65 \mathrm{~m}$.

Fig. 3.2
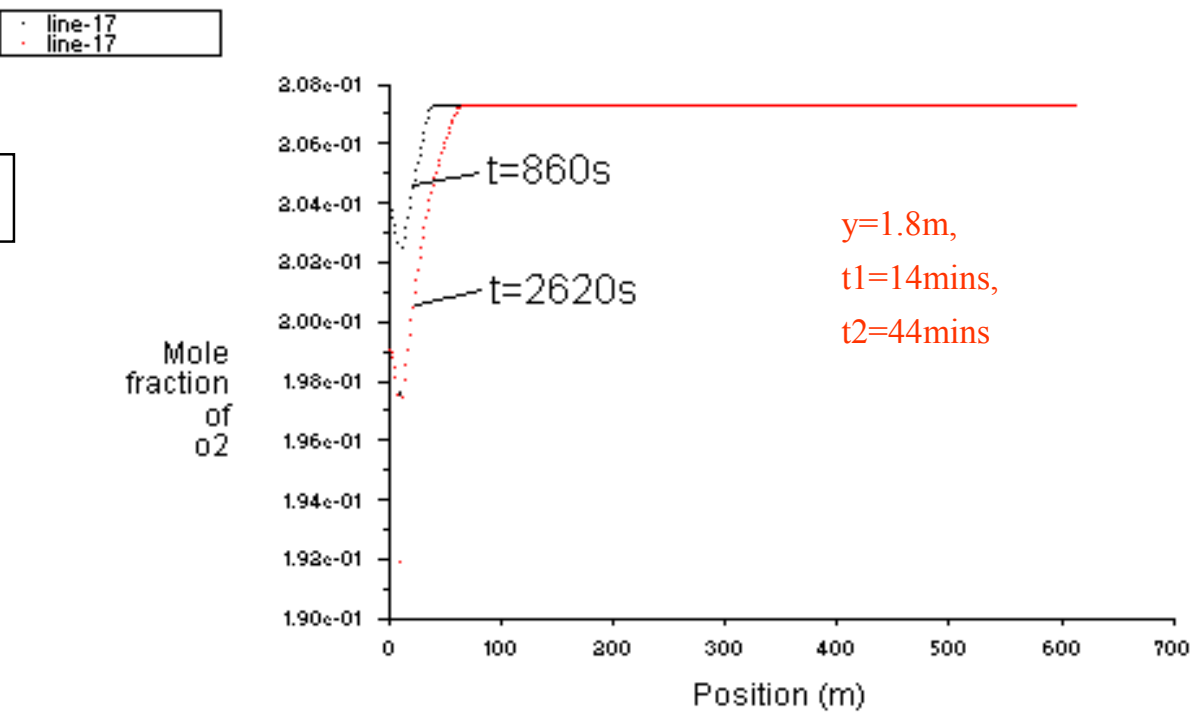
3.3 Mole fraction of $\mathrm{O} 2$ at $\mathrm{t}=11510 \mathrm{~s}$, the lowest $\mathrm{O} 2$ fraction is higher than $15.7 \%$.

Fig. 3.3
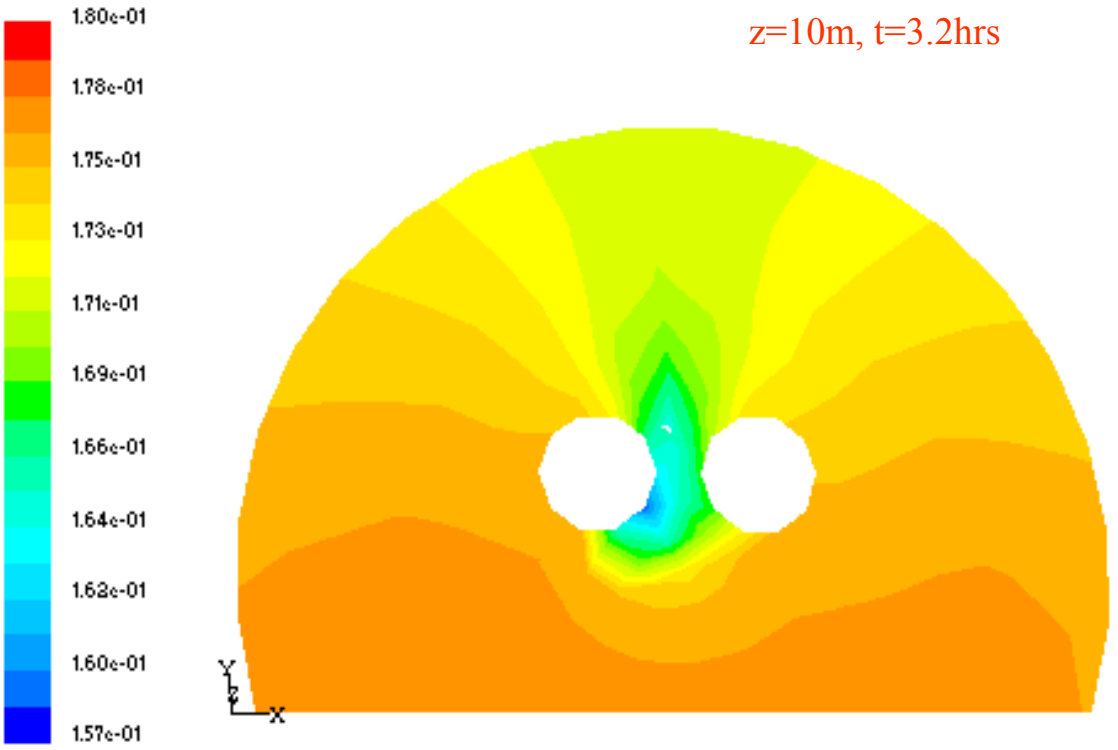

3.4 The $\mathrm{O} 2$ mole fraction profile at a height of $1.8 \mathrm{~m}$ above the ground of tunnel, along the axial direction of the sextant ( $\mathrm{z}$ coordinate). The discharging point is at $10 \mathrm{~m}$ in $\mathrm{z}$ direction, where presents the lowest $\mathrm{O} 2$ mole fraction. In a range between $\mathrm{z}=10 \mathrm{~m}$ and $\mathrm{z}=110 \mathrm{~m}$ along the tunnel (at $\mathrm{y}=1.8 \mathrm{~m}$ ), the $\mathrm{O} 2$ level increases from $18.5 \%$ to normal air at $\mathrm{t}=7270 \mathrm{~s}$. At $\mathrm{t}=11510 \mathrm{~s}$ the lowest is $17.5 \%$ and extended to normal air at $\mathrm{z}=190 \mathrm{~m}$.

Fig. 3.4
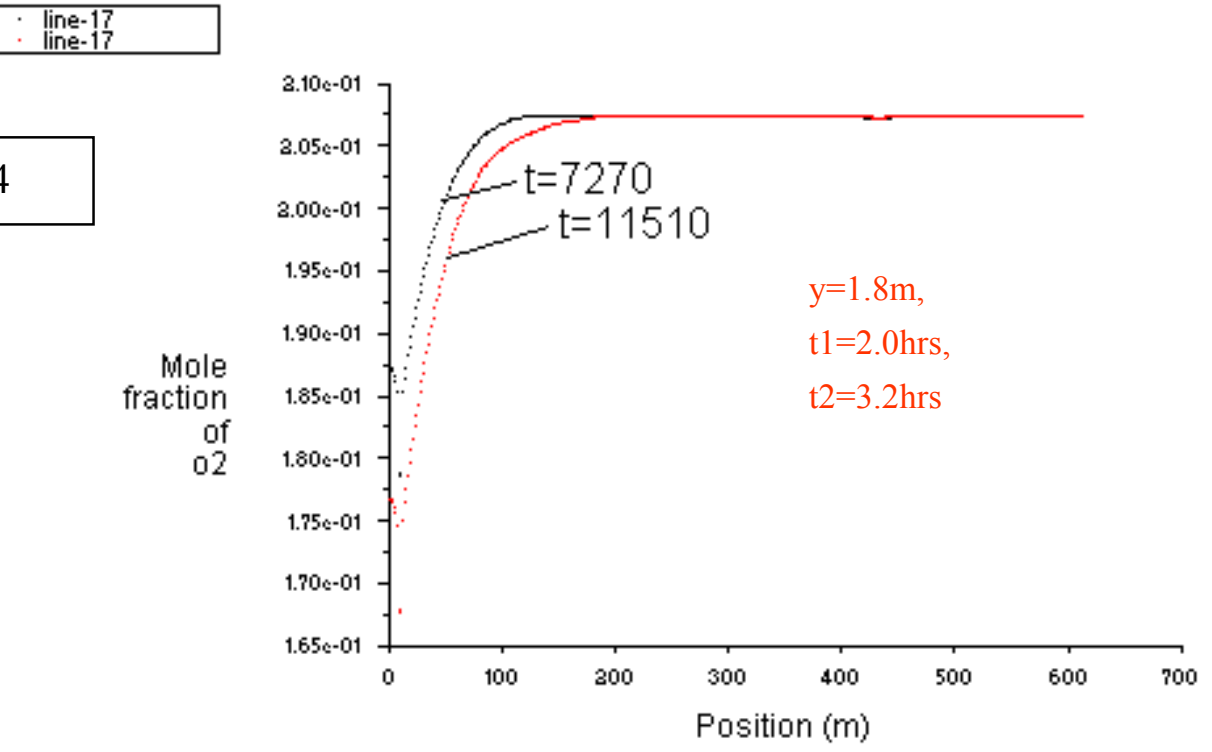
3.5 Contour of mole fraction of $\mathrm{O} 2$ at $\mathrm{z}=10 \mathrm{~m}$ (discharging point) at $\mathrm{t}=16510 \mathrm{~s}$.

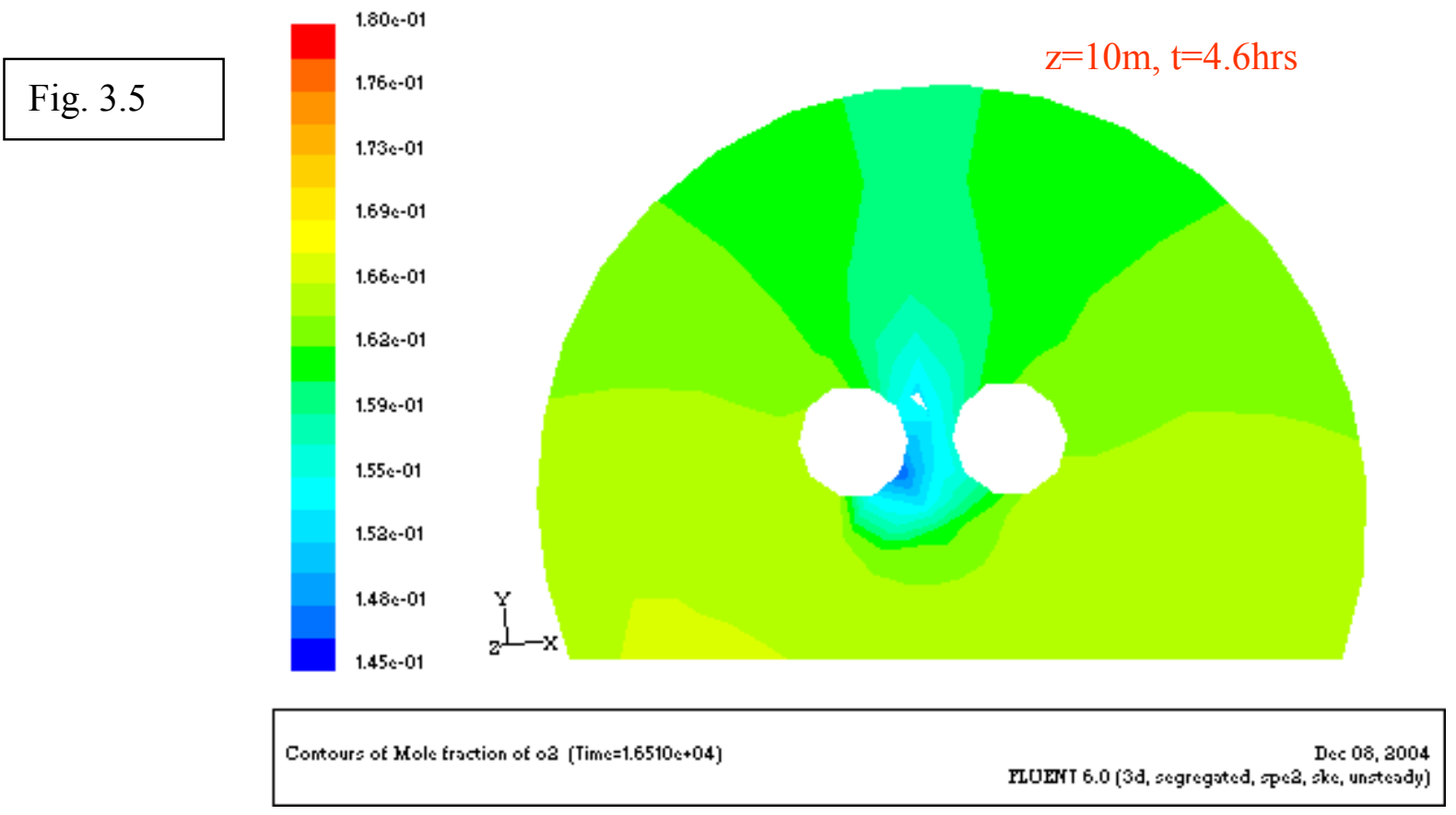

3.6 Contour of mole fraction of $\mathrm{O} 2$ at $\mathrm{z}=50 \mathrm{~m}$ at $\mathrm{t}=16510 \mathrm{~s}$

Fig. 3.6
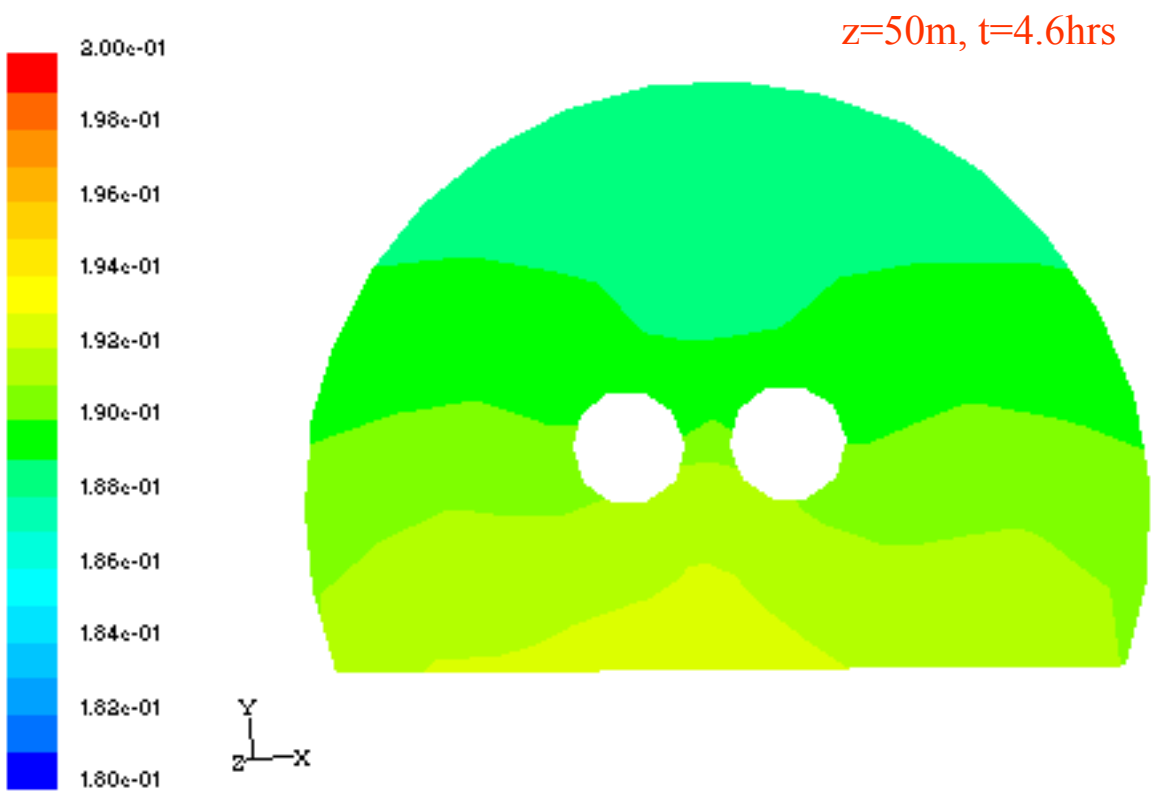

Contour 2 of Wole traction of o3 (Time $=1.6510 \mathrm{c}+04$ )

Dec 08, 2004

FLUसrT 6.0 [3d, zegregsted, spe3, skc, unstesdy) 
3.7 The $\mathrm{O} 2$ mole fraction profile at a height of $1.8 \mathrm{~m}$ above the ground of tunnel, along the axial direction of the sextant ( $\mathrm{z}$ coordinate).

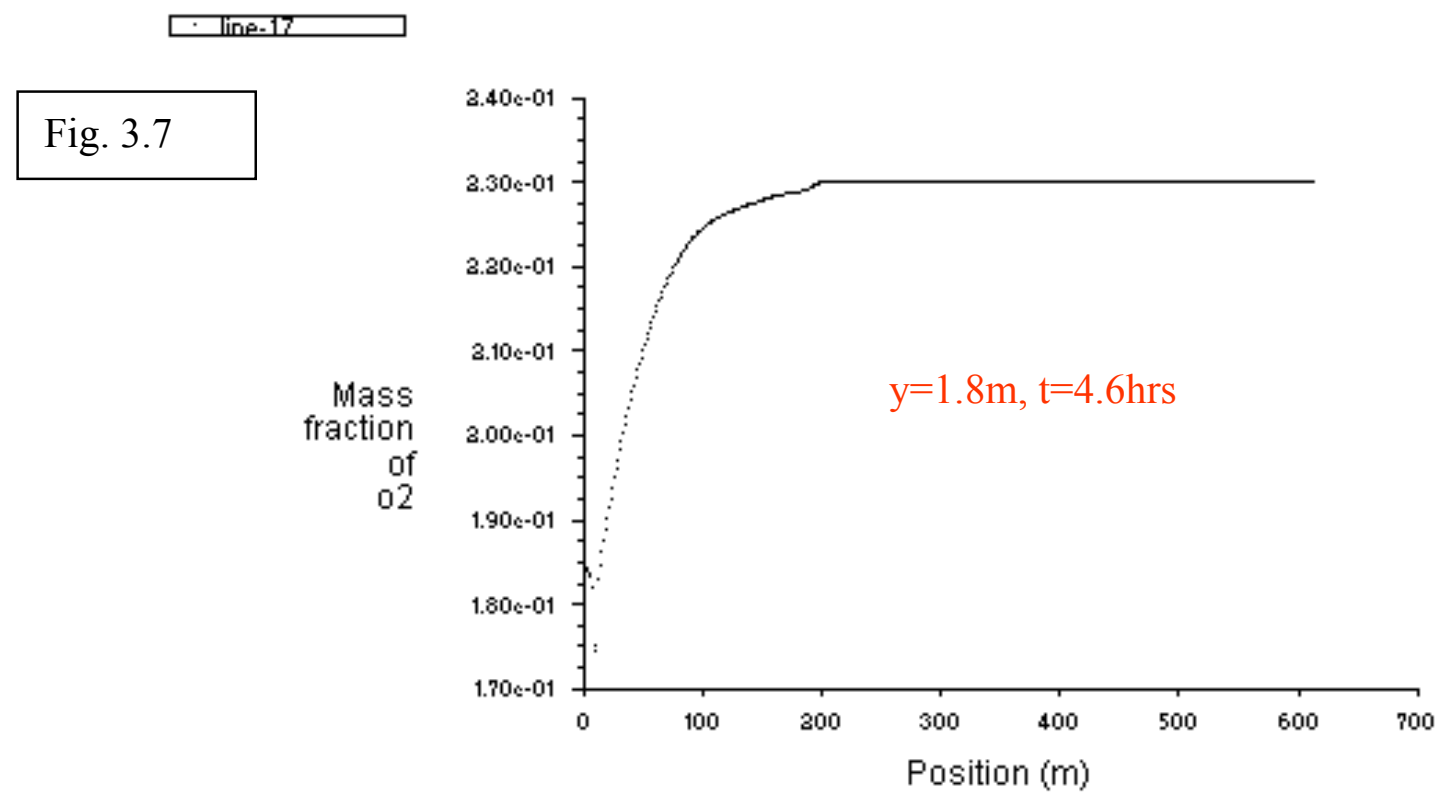

Wses traction of o3 (Time $=1.6510 \mathrm{c}+04)$

Dec 08,3004

FLUE⿰T 6.0 (3d, segregsted, Fec2, vke, unstesdy) 

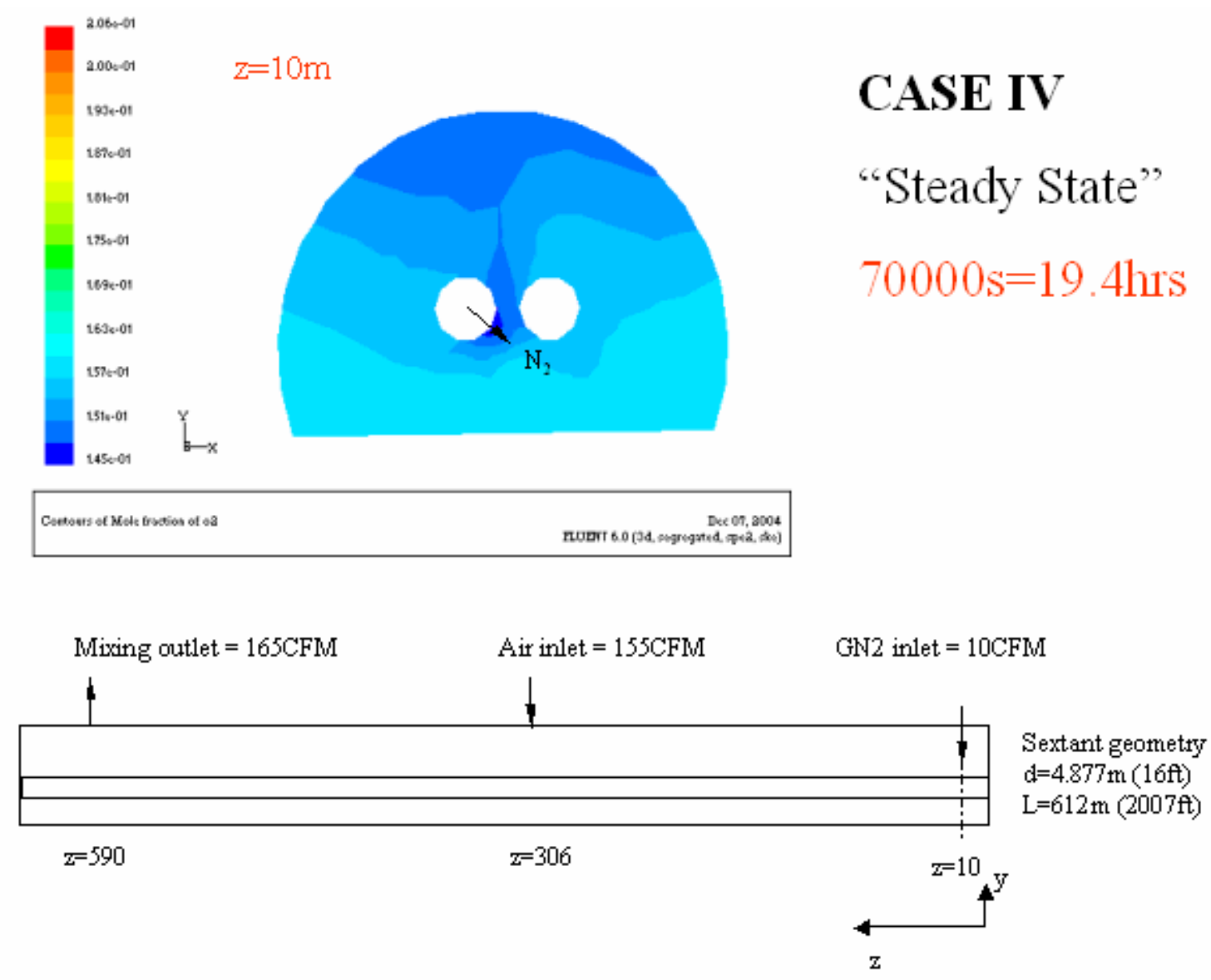

$12-9-04$ 
4.2 Contour of mole fraction of $\mathrm{O} 2$ at $\mathrm{z}=50 \mathrm{~m}$ in steady state.

Fig. 4.2

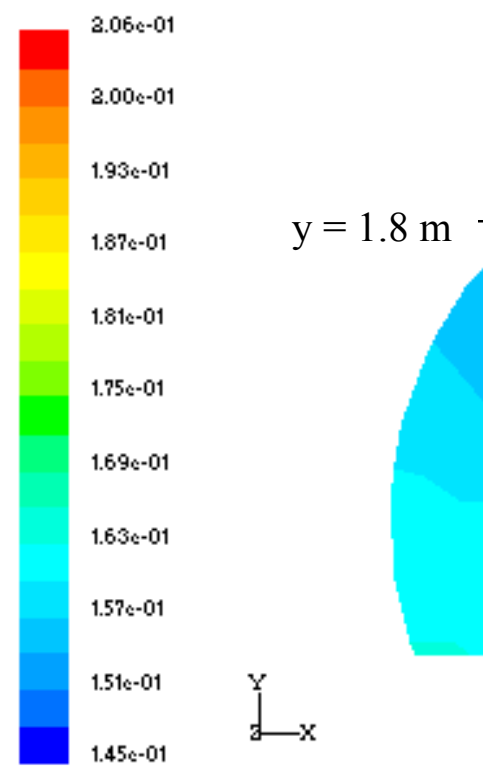

Contours of Wole traction of o3

4.3 Profile of mole fraction of $\mathrm{O} 2$ at $\mathrm{y}=1.8 \mathrm{~m}$ along $\mathrm{z}$ direction

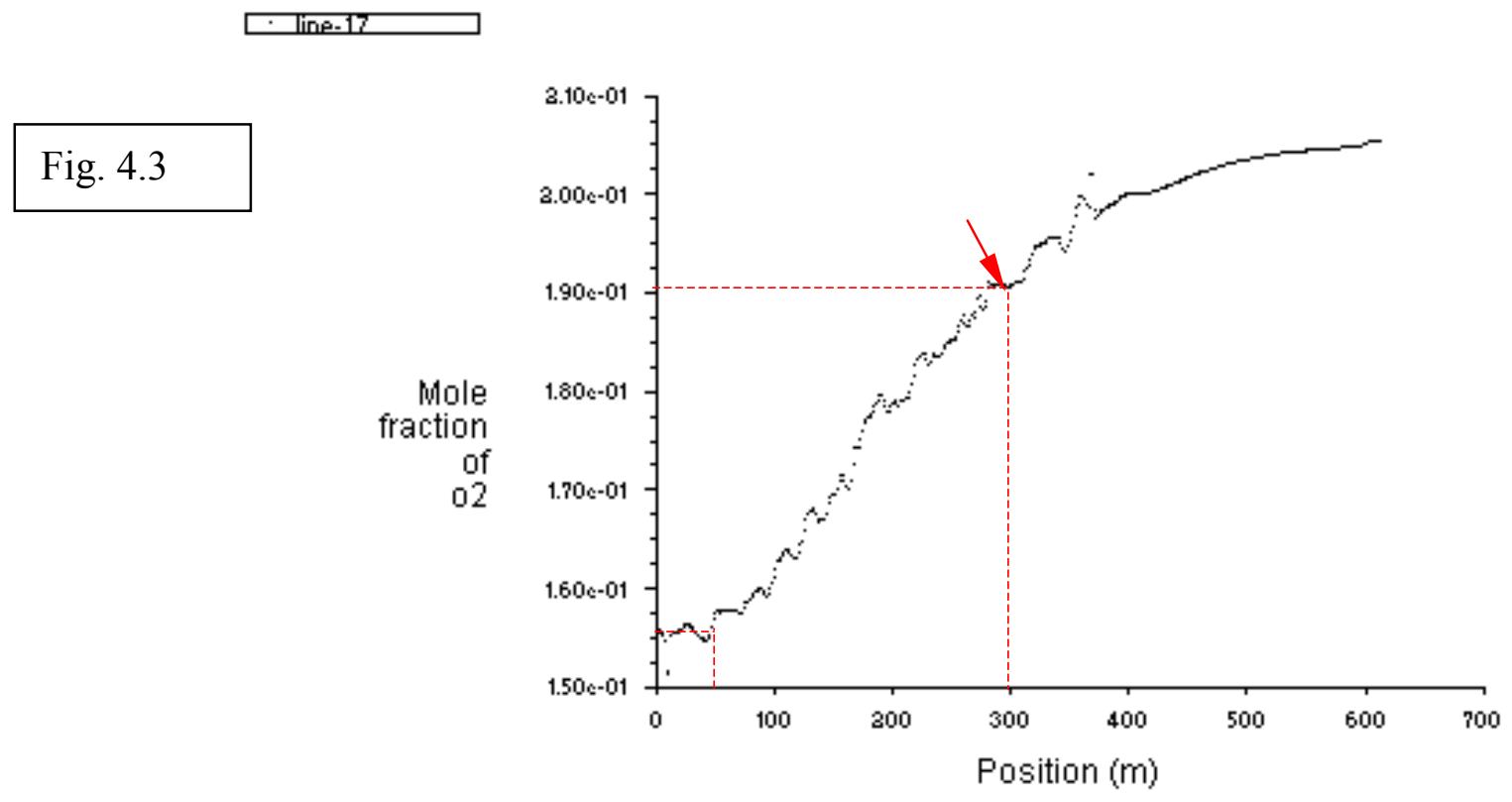




\section{CASE V}

Fig. 5.0

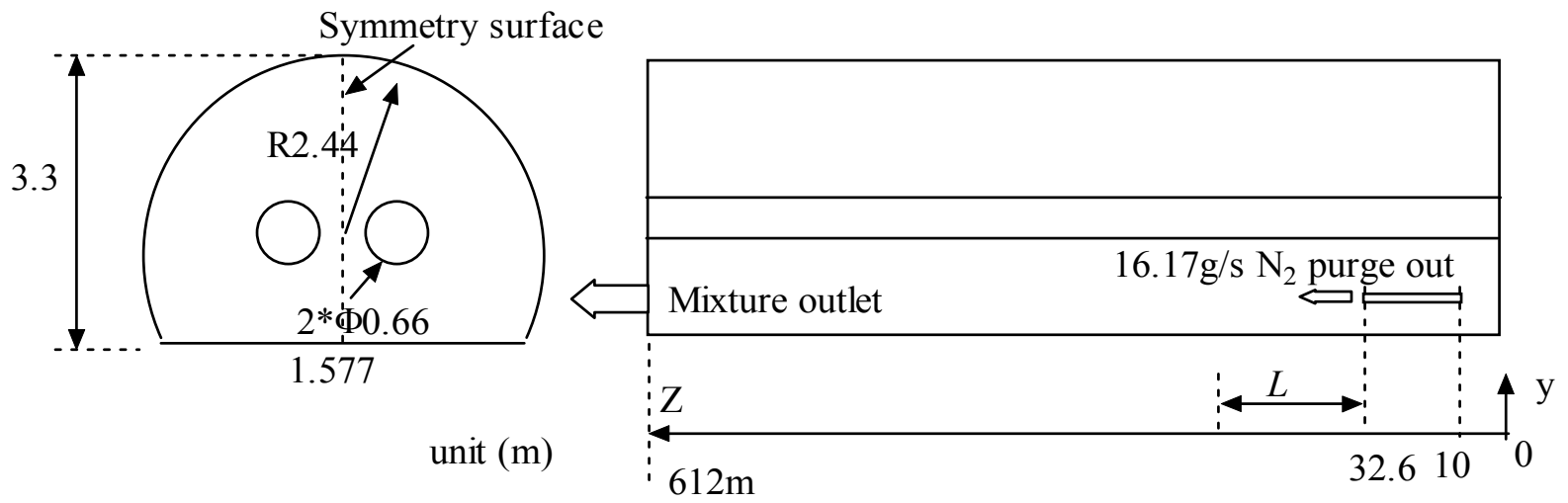

Fig.5.0 shows the cross section and straight length of one sextant. The room-temperature nitrogen from the magnets is purged into the tunnel by a "squirrel-cage" fan through an "elephant trunk" hose with inner diameter of $152.4 \mathrm{~mm}$. The "elephant trunk" hose in $22.6 \mathrm{~m}$ long runs from $\mathrm{z}=10 \mathrm{~m}$ to $\mathrm{z}=32.6 \mathrm{~m}$ in one side of the sextant.

The purging mass flow rate of $\mathrm{GN}_{2}$ is $16.17 \mathrm{~g} / \mathrm{s}$, while $83.54 \mathrm{~g} / \mathrm{s}$ air in tunnel is also sucked into the flow at $\mathrm{z}=10 \mathrm{~m}$, because of the high capacity of the fan. The mixture is then discharged into the same sextant at $z=32.6 \mathrm{~m}$. At the other end of sextant, locally mixed gas is discharged out of this sextant.

For the short length of the hose comparing with the total length of tunnel, the locally circulating mixture around the hose is considered to have inappreciable effects on species distribution in tunnel, especially for most of the spaces away from the hose, so is neglected.

Two cases are modeled to investigate $\mathrm{O}_{2}$ fraction variety at the ceiling just above the discharging point. One case is that the pure $\mathrm{N}_{2}$ is discharged into the tunnel horizontally and another is that $\mathrm{N}_{2}$ is discharged vertically. 


\section{$5.1 \quad \mathbf{N}_{2}$ discharging into the tunnel horizontally}

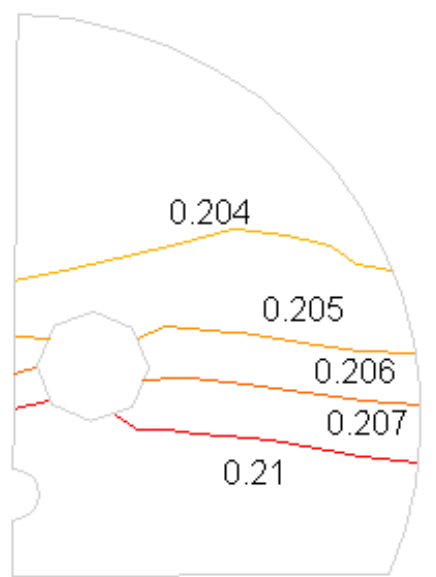

a. Mole fraction of $\mathrm{O}_{2}$ at $z=10 \mathrm{~m}$

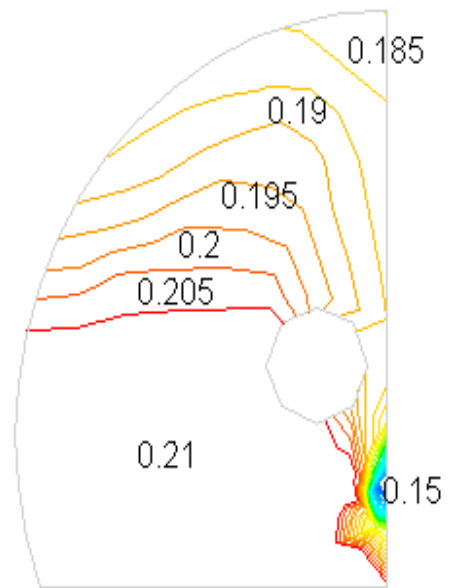

b. Mole fraction of $\mathrm{O}_{2}$ at $z=32.6 \mathrm{~m}$

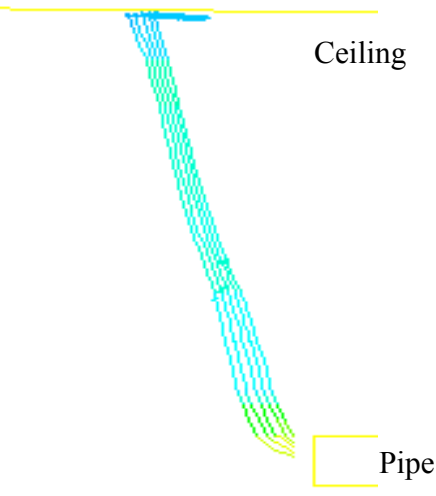

Floor

c. N2 flow path lines at purge

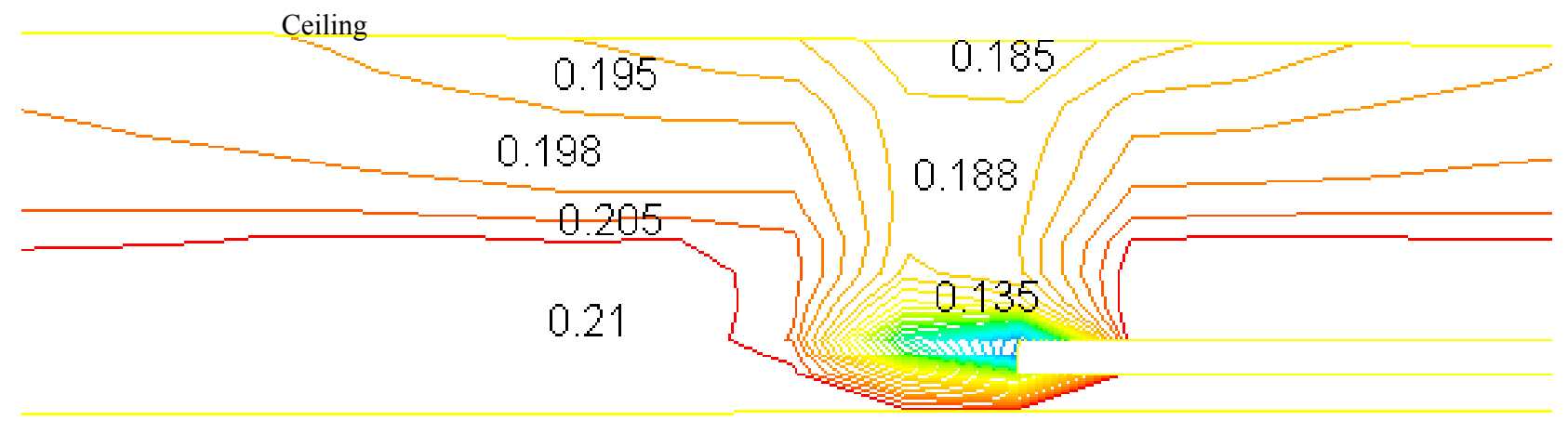

Floor

d. Mole fraction of $\mathrm{O}_{2}$ on symmetrical surface

Fig. 5.1.1 Results of numerical simulation at $t=829 \mathrm{~s}$

Fig. 5.1.1 shows the numerical simulation results of $\mathrm{N}_{2}$ with mass flow rate of $16.17 \mathrm{~g} / \mathrm{s}$ discharging into the tunnel in $t=829 \mathrm{~s}$. For the area at $\mathrm{z}=32.6 \mathrm{~m}$, the $\mathrm{O}_{2}$ fraction at the ceiling above the discharging point quickly drops to $18.66 \%$ at 150 s and to $18.5 \%$ at 829 s from initial $21 \%$, respectively.

For the area at $z=10 \mathrm{~m}$, the $\mathrm{O}_{2}$ fraction is only affected after about 5 minutes. It is $20.8 \%$ at $t=329 \mathrm{~s}$ and $20.4 \%$ at $t=829 \mathrm{~s}$. If the nearest oxygen sensor fitted in the ceiling at "working area," $\mathrm{z}=10 \mathrm{~m}$ where is $22.6 \mathrm{~m}$ away from the discharging point, it will alarm when the local $\mathrm{O}_{2}$ mole fraction drops to $19 \%$ after about 2.5 hours, which is revealed by the simulation. However, the $\mathrm{O}_{2}$ mole fraction near the discharging point, $\mathrm{z}=32.6 \mathrm{~m}$ has already dropped below $19 \%$ for over 
2 hours. For the worst-case scenario, if any incidental breaks or failed bypass of the "squirrel-cage" or "elephant trunk", close to where people happen to work, the ODH will take place.

It is also found from Fig. $5.1 \mathrm{~b}$ that the content of $\mathrm{O}_{2}$ in center is lower than that at each side of the dome and it is always true for other cross sections along the tunnel, which revealed by the simulation.

The discharging velocity of $\mathrm{GN}_{2}$ from the pipe is small and its disturbance to the fluid in tunnel is limited and localized. The molecules of $\mathrm{N}_{2}$ go up right away from the hose in form of approximate bias, see Fig. $5.1 \mathrm{c}$, then they flow in adversely direction of air flow after get to the ceiling.

\section{1 .2}

Fig. 5.1.2 shows the changes of mole fraction of $\mathrm{O}_{2}$ with time at ceiling of the tunnel in different distances from the $\mathrm{N}_{2}$ discharging point. The corresponding times that content of $\mathrm{O}_{2}$ still keeps $21 \%$ at $L=50 \mathrm{~m}, 100 \mathrm{~m}, 150 \mathrm{~m}$ are about $1250 \mathrm{~s}, 4250 \mathrm{~s}, 8050 \mathrm{~s}$, respectively. The contents of $\mathrm{O}_{2}$ of these points drop linearly after a period of time, say, about 4 hours.

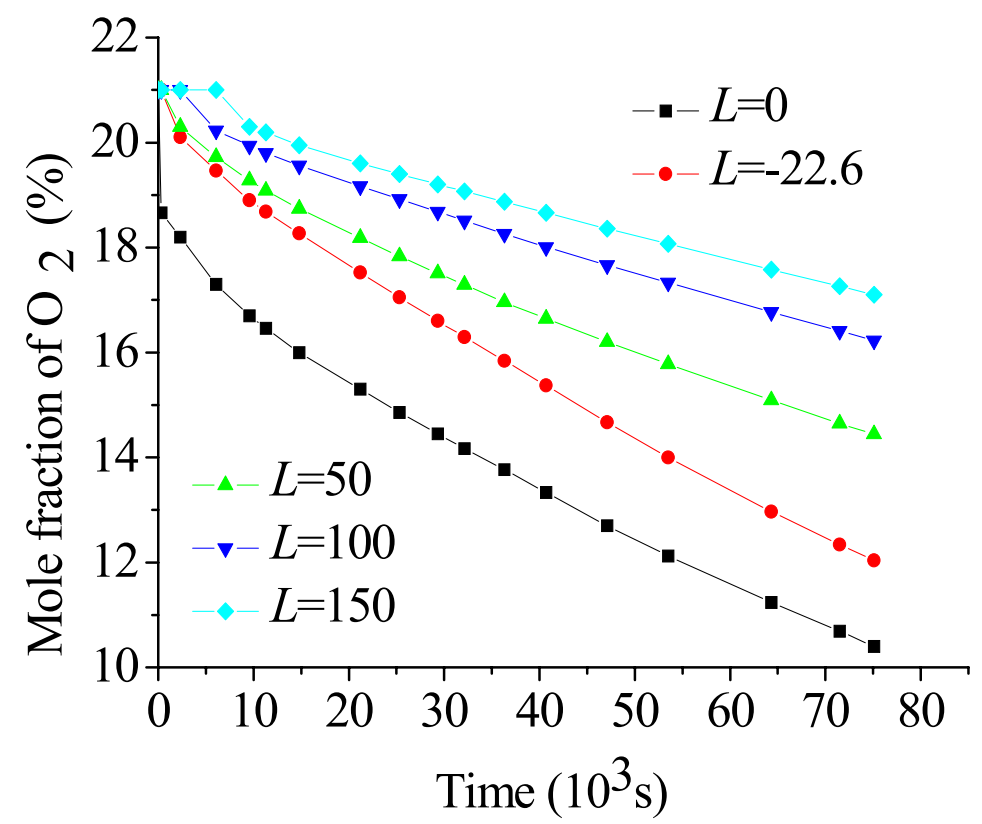

Fig. 5.1.2 Mole fraction of $\mathrm{O}_{2}$ at points of ceiling of tunnel and at different distances $L$ from discharging point changes with time. 


\section{1 .3}

Assuming the average height of the person working in tunnel is $1.8 \mathrm{~m}$, Fig. 5.1.3 gives the distribution of mole fraction of $\mathrm{O}_{2}$ along the tunnel at height of $1.8 \mathrm{~m}$ at different time. The propagation velocity of $\mathrm{N}_{2}$ wave front (boundary of affected zone) decreases with time as expected because of the huge volume of tunnel. The velocity that $\mathrm{N}_{2}$ wave front moves from $z=150 \mathrm{~m}$ to $z=205 \mathrm{~m}$ is $12.2 \mathrm{~mm} / \mathrm{s}$, and it is $11.1 \mathrm{~mm} / \mathrm{s}$ from $z=205 \mathrm{~m}$ to $z=255 \mathrm{~m}$. It takes about $75109 \mathrm{~s}, 21$ hours, to move to $z=475 \mathrm{~m}$.

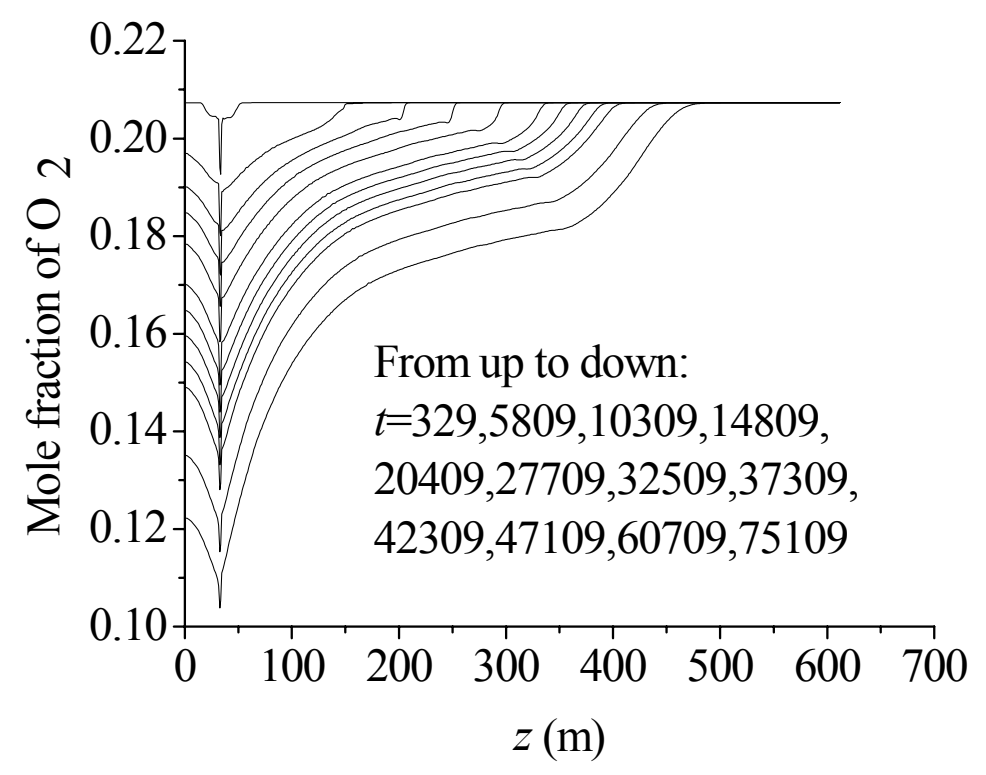

Fig. 5.1.3 Mole fraction of $\mathrm{O}_{2}$ at height of $1.8 \mathrm{~m}$ on symmetry surface at different times. 


\section{2 $\quad \mathrm{N}_{2}$ discharging into the tunnel vertically}

For the case of $\mathrm{N}_{2}$ discharging vertically into the tunnel and maintaining other boundary conditions unchanged from the horizontal case, the simulation results at $t=830 \mathrm{~s}$ is given in Fig. 5.2. $\mathrm{O}_{2}$ fraction at ceiling at $z=32.6 \mathrm{~m}$ drops a little bit compared with the results in Fig. 5.1 at same time frame. No obvious discrepancies are found for those points beyond $z=82.6 \mathrm{~m}$ for long enough time.

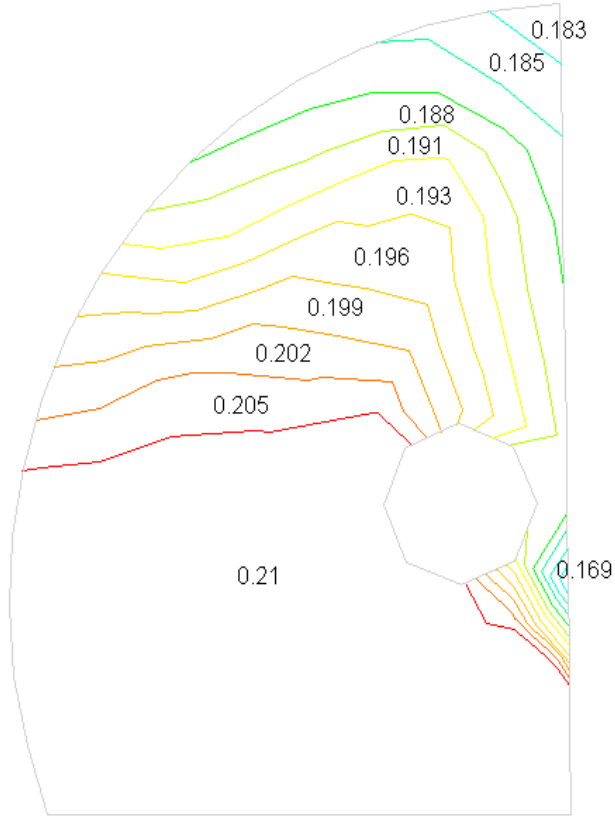

a. Mole fraction of $\mathrm{O}_{2}$ at $z=32.6 \mathrm{~m}$

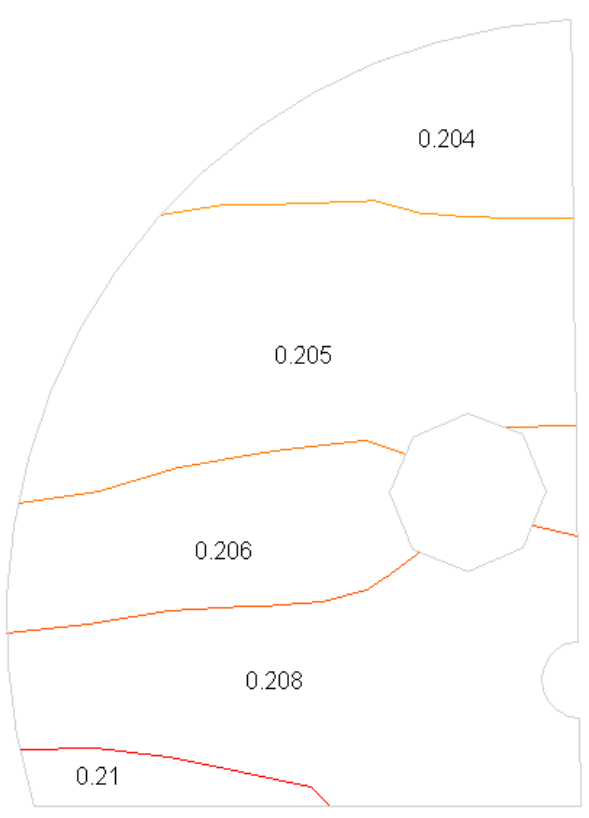

b. Mole fraction of $\mathrm{O}_{2}$ at $z=10 \mathrm{~m}$

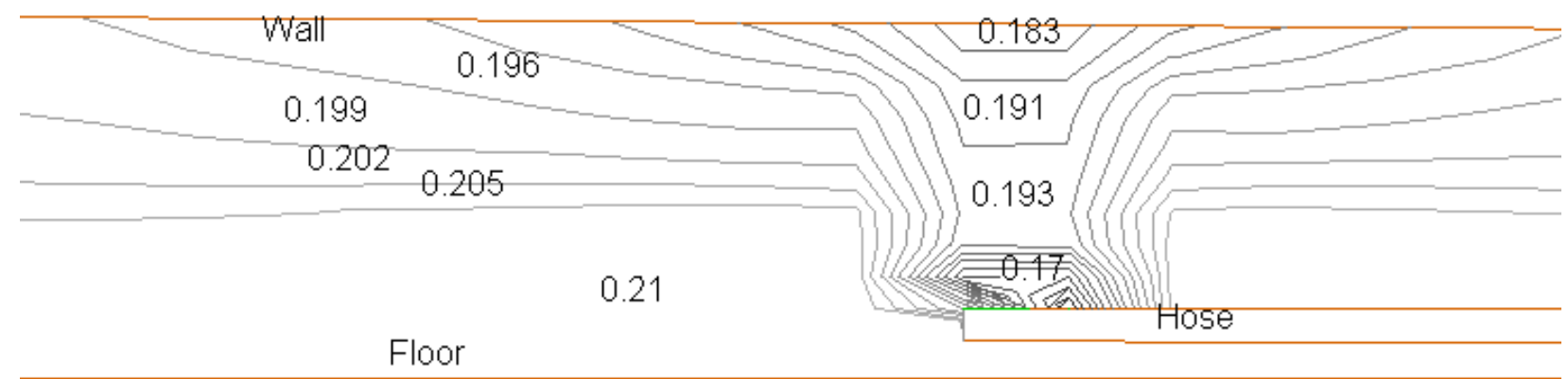

c. Mole fraction of $\mathrm{O}_{2}$ on vertical symmetrical surface

Fig. 5.2 Results of numerical simulation at $t=830 \mathrm{~s}$ 


\subsection{Comparison of two cases}

Fig. 5.3 shows mole fraction of $\mathrm{O}_{2}$ at the point on the ceiling at $\mathrm{z}=32.6 \mathrm{~m}$ changes with time both for vertically and horizontally discharging with same mass flow rate. The $\mathrm{O}_{2}$ fraction changes corresponding to the vertically case is somewhat faster than to the horizontally case assuming both discharging velocities are same and small.

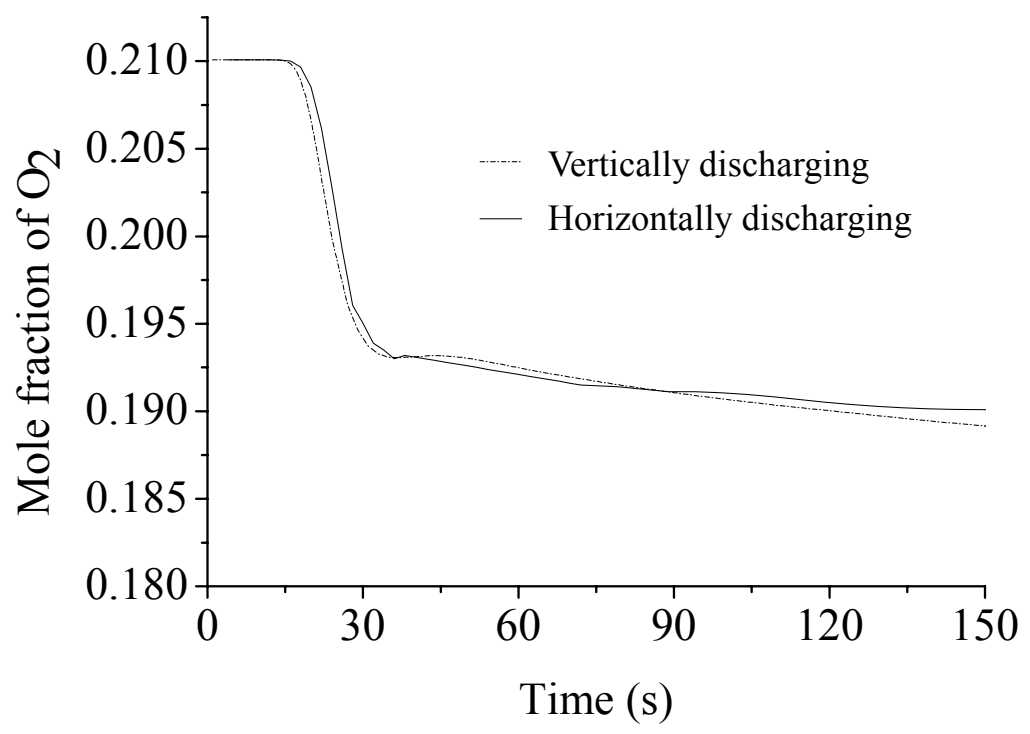

Fig. 5.3 Mole fraction of $\mathrm{O}_{2}$ at points on ceiling at $\mathrm{z}=32.6 \mathrm{~m}$

\section{End of report}




\section{$\underline{\text { Appendix } 1}$}

\section{Memo}

Accelerator Systems Safety Review Committee

date: $\quad$ October 11, 2004

to: $\quad$ J. W. Glenn

from: $\quad$ G.T. McIntyre

subject: $\quad$ Minutes from RHIC Tunnel Feedback Meeting held 09/14/04

Attendees: $\quad$ L. Jia, J. W. Glenn, G. McIntyre

The meeting was held to initiate an investigation into possible oxygen deficiency hazards caused by controlled and uncontrolled release of nitrogen purge gas into the RHIC tunnel. (See ASSRC minutes, "SubCommittee Meeting on ODH Controls at RHIC Related to Nitrogen Purge Gas Safety", dated $08 / 05 / 04)$

W. Glenn tasked L. Jia with running calculations to determine the possible ODH due to the flow of 10 CFM of nitrogen gas into the tunnel. After further review this flow was increased to 30 CFM total.

Glenn ask McIntyre to provide Jia with the following information:

1. The velocity of the output air from the "squirrel-cage" fans used in the purge gas evacuation system. Test performed by R. Anderson using a calibrated "hot-wire" anemometer revealed these results:

Unrestricted maximum performance of system

- Each of the four 1.5" ID inlet hoses to the fan had a maximum flow of 62 CFM with the inlets unrestricted.

- The maximum flow from the fan's 24 foot, 6"ID outlet hose was 230 CFM total. Increasing the air pressure at the inlet did not increase the flow at the outlet.

Simulated In-tunnel maximum performance of system

- The four 1.5" ID inlet hoses to the fan were restricted to a $1 / 2$ " inlet hole.

- The maximum flow from the fan's 24 foot, 6"ID outlet hose was reduced to 165 CFM total. Increasing the air pressure at the inlet did not increase the flow at the outlet.

2. Volume of a tunnel sector, removing the volume of the superconducting magnets.

The volumes below are taken from the Sextant 1 Emergency Ventilation drawing SK-1. sector $12-16 \mathrm{ft}$ plate region -1 23800

sector $12-16 \mathrm{ft}$ plate region -2 13500

sector $12-16 \mathrm{ft}$ plate region -3 37100

sector $12-16 \mathrm{ft}$ plate region -4 26180

sector $12-16 \mathrm{ft}$ plate region -5 
sector 1 - $16 \mathrm{ft}$ plate region -1

26180

sector 1 - $16 \mathrm{ft}$ plate region -2

26180

sector 1 - $16 \mathrm{ft}$ plate region -3

34150

sector 1 - $16 \mathrm{ft}$ plate region -4

16030

sector $1-16 \mathrm{ft}$ plate region -5

12880

sector 1 - $20 \mathrm{ft}$ plate region -5

341510

604945

\section{Triplet volume}

D0 end can

D0

Q1D0 interconn

Q1

Q1Q2 interconn

Q2

Q2Q3 interconn

Q3

Q3 end can

Q3 end can interconn

Magnet volume

(over 1440 feet long $X$ 2) length

33.5

140

115.2

483

59.48

249

57.8

242

37.75

158

163.8

686

37.75

158

139.8

586

37.63

158

41.28

173

3033

1440

10619

Magnet volume total

13651

\section{Net Volume}

Tunnel volume - magnet volume

591294

3. Determine the approximate distance from the fan outlet to barricade.

- Estimates put this distance at 15 feet.

4. Drawing showing tunnel geometry and a sketch of the purge gas evacuation system.

- pdf of SK-1 and AutoCAD drawing, "Tunneldimensions.dwg", are attached showing tunnel geometry, as well as "Pgasevac1.dwg" showing a schematic of the purge gas evacuation system. 
Appendix 2

\section{SEXTANT 121 LAYOUT}

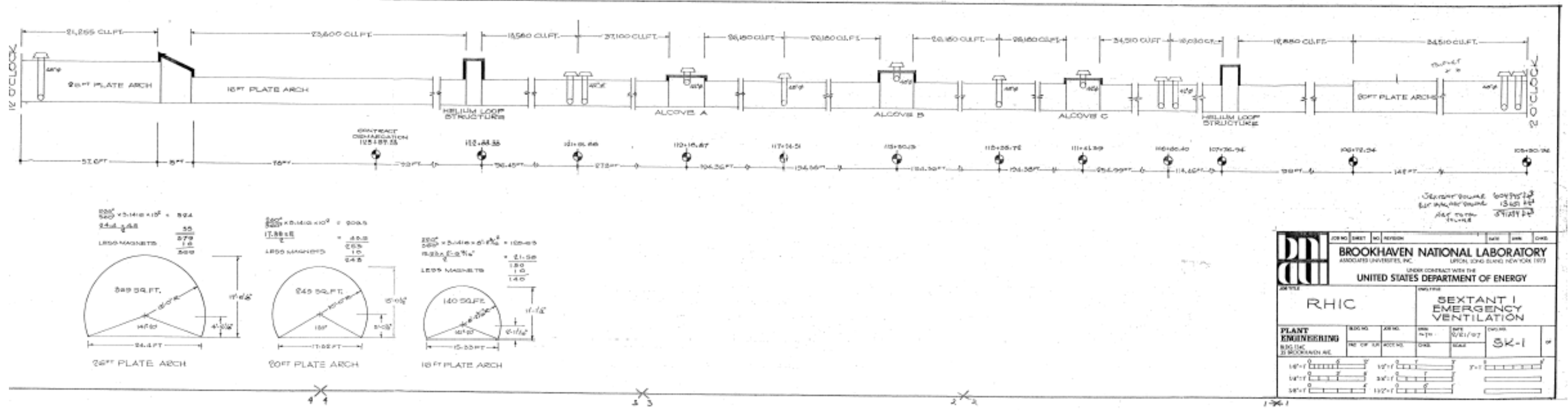


Appendix 3

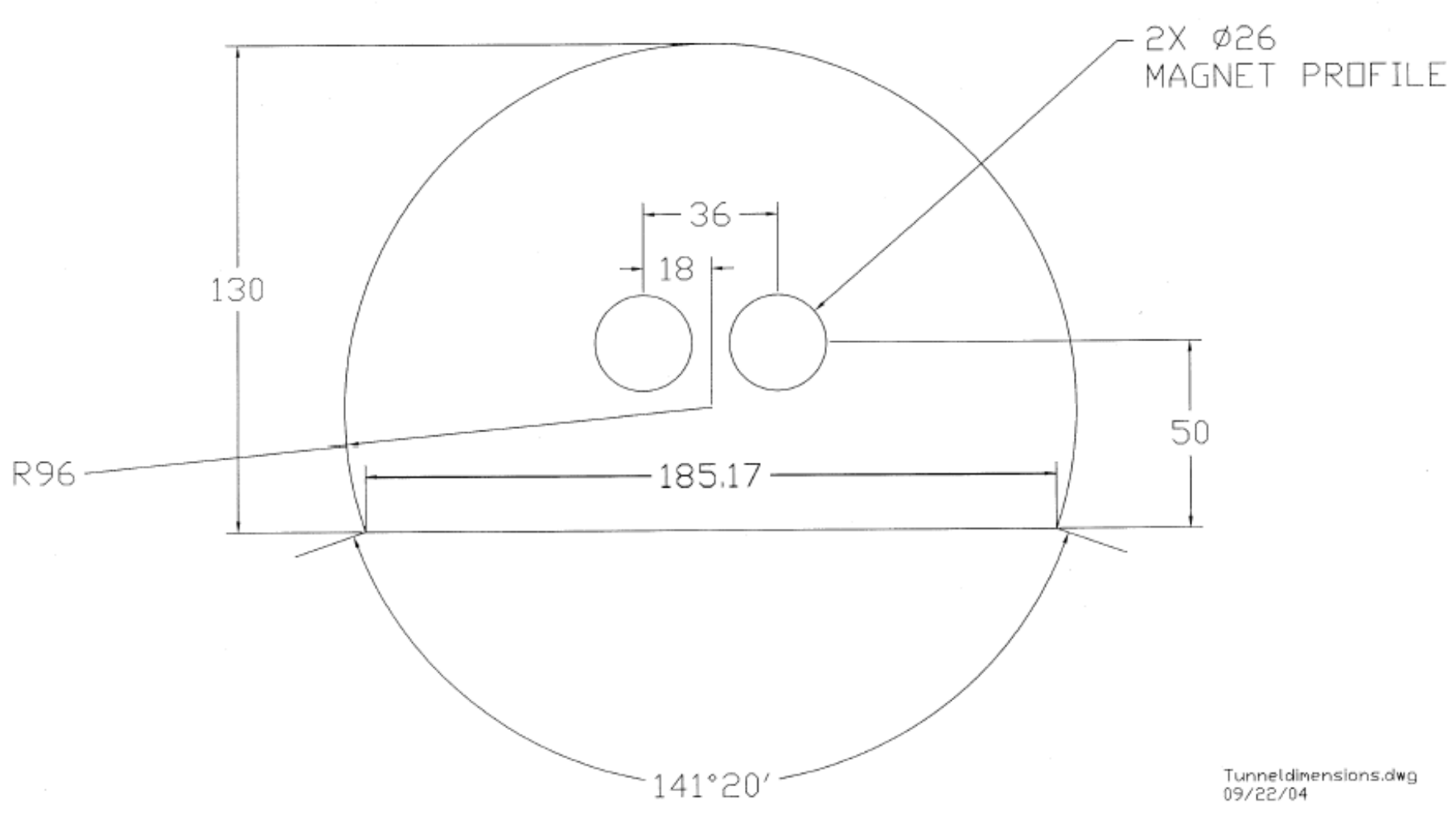

Ф 16 FT TUNNEL SECTION ALL DIMENSIONS IN INCHES 
Appendix 4

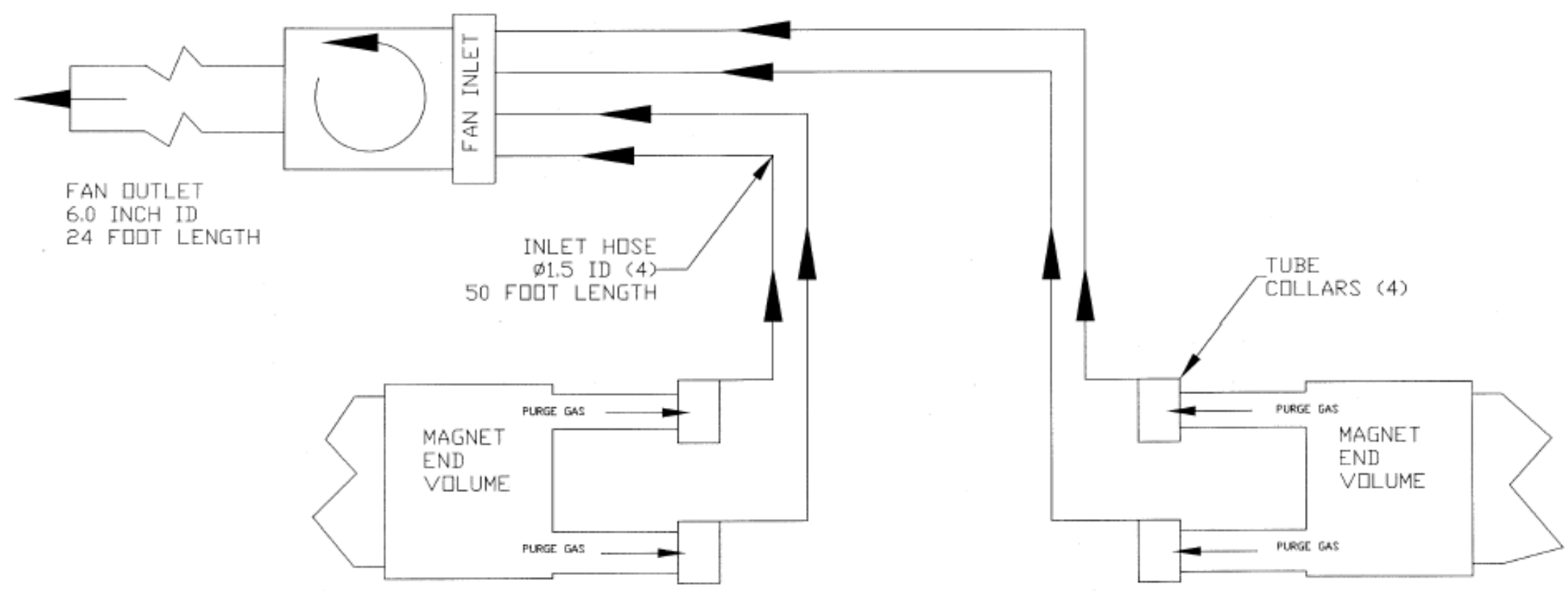

SCHEMATIC DF PURGE GAS EVACUATION SYSTEM

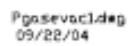




\begin{tabular}{|c|c|c|c|c|c|c|c|c|}
\hline Flow out of evac system with 1/2" holes @ inlets (4) & 165 & CFM & & & & & & \\
\hline Flow from N2 purge gas (max.) & 30 & CFM & & & & & & \\
\hline Therefore, the purge gas is what $\%$ of total flow? & 0.18 & & & & & & & \\
\hline Nitrogen is what $\%$ of ambient air? & 0.78 & & & & & & & \\
\hline Air Nitrogen is what $\%$ of mixed air? ${ }^{* * * *}$ & 0.638181818 & & & & & & & \\
\hline Ambient + purge N2 is what percentage of outlet gas & 0.82 & & & & & & & \\
\hline This leaves less than & 0.18 & $\mathrm{O} 2$ & & & & & & \\
\hline \multirow[t]{3}{*}{$\%$ of $\mathrm{O} 2$ in ambient air is approximately } & 0.21 & & & & & & & \\
\hline & & \multicolumn{6}{|c|}{ is needed to cause the POM to alarm at the inlet. } & \\
\hline & CFM N2 & 2 & 5 & 10 & 15 & 20 & 30 & 50 \\
\hline $165-N 2$ & CFM air & 163 & 160 & 155 & 150 & 145 & 135 & 115 \\
\hline$(\mathrm{CFM}$ air * $.785+$ CFM N2)/ 165 & $\mathrm{N} 2 \%$ & $78.76 \%$ & $79.15 \%$ & $79.80 \%$ & $80.45 \%$ & $81.11 \%$ & $82.41 \%$ & $85.02 \%$ \\
\hline \multirow[t]{2}{*}{$1-\% \mathrm{~N} 2$} & O2 \% & $21.24 \%$ & $20.85 \%$ & $20.20 \%$ & $19.55 \%$ & $18.89 \%$ & $17.59 \%$ & $14.98 \%$ \\
\hline & @hose end & & & & & $* * * *$ & & \\
\hline
\end{tabular}

